\title{
Determination of Optimum Conditions for the Production of Activated Carbon Derived from Separate Varieties of Coconut Shells
}

\author{
E. S. Sanni, ${ }^{1}$ M. E. Emetere, ${ }^{2}$ J. O. Odigure, ${ }^{3}$ V. E. Efeovbokhan, ${ }^{1}$ \\ O. Agboola, ${ }^{1}$ and E. R. Sadiku ${ }^{4}$ \\ ${ }^{1}$ Department of Chemical Engineering, Covenant University, PMB 1023, Ogun State, Nigeria \\ ${ }^{2}$ Department of Physics, Covenant University, PMB 1023, Ogun State, Nigeria \\ ${ }^{3}$ Department of Chemical Engineering, Federal University of Technology, PMB 65, Niger State, Nigeria \\ ${ }^{4}$ Department of Chemical, Metallurgical and Materials Engineering, Tshwane University of Technology, Pretoria, South Africa \\ Correspondence should be addressed to E. S. Sanni; adexz3000@yahoo.com
}

Received 6 January 2017; Revised 18 April 2017; Accepted 24 April 2017; Published 3 August 2017

Academic Editor: Sankar Chakma

Copyright (C) 2017 E. S. Sanni et al. This is an open access article distributed under the Creative Commons Attribution License, which permits unrestricted use, distribution, and reproduction in any medium, provided the original work is properly cited.

\begin{abstract}
Activated carbons were produced from coconut shells of tall and dwarf tree varieties. The activated carbon from the tall tree variety was initially synthesized using $1 \mathrm{M}$ concentration of each of $\mathrm{ZnCl}_{2}, \mathrm{H}_{3} \mathrm{PO}_{4}$, and $\mathrm{KOH}$ solutions. From the adsorptive tests conducted using methylene blue solution, the activated carbon produced with $\mathrm{H}_{3} \mathrm{PO}_{4}$ gave the best absorbance and adsorptive performance. Coconut shells of dwarf tree variety were then obtained and treated with same mass of coconut shells of the tall tree variety using varied concentrations of the acid in order to determine whether the optimum concentration and temperature for producing carbon black from the coconut shells are distinct or similar for both varieties. The process was also modelled using the Differential Response Method (DRM) in order to determine the yields and adsorptive performances of the activated carbons by varying the carbonization temperature and concentration. The results from experiment and the developed mathematical model were both found to be in agreement giving the optimum concentration of phosphoric acid and $\mathrm{pH}$ for producing activated carbon to be $0.67 \mathrm{M}$ and 2.07 for the tall tree variety and $1 \mathrm{M}$ and 1.98 for the dwarf variety at optimum temperatures in the range of $450-575^{\circ} \mathrm{C}$ and $575^{\circ} \mathrm{C}$, respectively.
\end{abstract}

\section{Introduction}

Activated carbon, a carbonaceous material with characteristic surface area and highly developed porous structure, consists of 87 to $97 \%$ carbon with other trace elements [1]. It can be produced from coal, wood, agricultural, and paper wastes for the adsorption of methylene blue [2]. Applications of activated carbon include air and water purification, water filtration, ground water remediation, adsorption of poisons, and drug overdoses. These and several other reasons are behind its increased market demand. According to [3], its preparation involves carbonization of the precursor below $800^{\circ} \mathrm{C}$ in an inert atmosphere before carbonization. In this research, coconut shells were used because they are cheap and readily available in Nigeria. The shells contain volatile matter and moisture that are removed by the application of heat [4]. Gratuito et al. [5] carried out process optimization of activated carbon yield produced from coconut shells using RSM. Different methods are available for producing activated carbon but for specific industrial application, a solid adsorbent with wide pore size distribution can be preferably obtained via chemical activation [6]. Activated carbons obtained from snail shells and apple peels were discussed [6, 7]. Hung [8] used a fluidized bed reactor to convert crushed coconut shells to activated carbon, syngas, bio-oils, and water while, in [9], bamboo was used to prepare activated carbon of high surface area. The various methods for preparing activated carbon from carbon precursors are contained in [10]. Karacan et al. 
[11] optimized the manufacturing conditions for producing activated carbon from lignite. Ketcha et al. [12] prepared activated carbon from maize cobs using zinc chloride as activating agent. The reduction of hexamine III cobalt was carried out using activated carbon produced from coconut shells as catalyst [13], while the work of Mourao et al. [14] considered the influence of oxidation on the adsorptive capacity of activated carbon synthesized from lignocellulosic precursors. The preparation and characterization of activated carbons from cellulosic waste materials for waste water treatment were carried out [15-17]. Before carbonization, the raw materials are impregnated with chemicals such as acid, strong base, or salt [18]. Production and characterization of activated carbons from coconut shells were discussed [19]; their adsorption capacities were determined by contacting them separately with methyl red and potassium permanganate. Shalna and Yogamoortthi [20] produced activated carbon with high chromium removal efficiency from tea dust using $\mathrm{H}_{3} \mathrm{PO}_{4}$ as the activating agent. Sodeinde [21] used activated carbon produced from coconut shells impregnated with $\mathrm{ZnCl}_{2}$ to obtain cobalt II from cobalt III, and the results were similar to those of Long et al. [13]. Bagasse, apricot stones, hazelnut, almond, pistachio, and walnut hard shells when used as precursors for producing activated carbon show that activation temperature/time and chemical-to-carbon impregnation ratio are important parameters for determining the quality of activated carbon [22]. Coconut fibre was used for synthesizing activated carbon using $\mathrm{H}_{3} \mathrm{PO}_{4}$ as activating agent [23]. Several works on synthesis of activated carbon via chemical activation involve the use of popular chemicals such as $\mathrm{H}_{3} \mathrm{PO}_{4}, \mathrm{ZnCl}_{2}$ and $\mathrm{KOH}$ as activating agents; however, $\mathrm{H}_{3} \mathrm{PO}_{4}$ is preferred to $\mathrm{ZnCl}_{2}$ because of the adverse effect $\mathrm{ZnCl}_{2}$ has on the environment, hence the reason for its limitation in use in the food and pharmaceutical industries [24]. The use of other raw materials such as rubber, wood dust [24], and sugar cane bagasse pith [25] has also been exploited as raw materials for producing activating carbon. Tan et al. [26] also conducted an optimization study on activated carbon produced from coconut husk which was found suitable for the removal of 2,4,6-trichlorophenol using $\mathrm{KOH}$ treatment and $\mathrm{CO}_{2}$ gasification. This paper focuses on determining the optimum temperature and concentration for the synthesis of activated carbon with excellent adsorptive performance using DRM since previous works had their intents on obtaining the best activating agent, carbon yield, carbon-to-chemical impregnation ratio, and so forth. The mathematical approach widely used is RSM. Till date, no research work states the optimum temperature and concentration(s) of $\mathrm{H}_{3} \mathrm{PO}_{4}$ required for producing one or more varieties of coconut shell activated carbon; again, this brings to mind the need to find out if the optimum conditions for producing activated carbon with excellent adsorptive performance is the same for separate varieties of coconut shells.

\section{Equipment, Materials, and Reagents}

2.1. Raw Materials, Chemicals, and Reagents. The materials and reagents used include coconut shells from tall and dwarf trees, distilled water, $0.3 \mathrm{M}, 0.5 \mathrm{M}, 0.67 \mathrm{M}$, and $1.33 \mathrm{M}$ concentrated phosphoric acid of $99 \%$ purity manufactured by Sigma-Aldrich, 95\% pure zinc chloride pellets made by MRS Scientific Ltd., $1 \mathrm{M} \mathrm{KOH}$ of $85 \%$ purity, made by Sigma-Aldrich and methylene blue dye, buffer solutions $4.01 \pm 0.02$ (colour-coded pink, HACH 22835-48, 1L) and $7.01 \pm 0.02$ (colour-coded yellow, HACH 22835-49, $0.5 \mathrm{~L}$ ) for $\mathrm{pH}$ meter calibration made by HM Digital Inc., USA, measuring cylinder, flat bottom flasks, conical flask, and beakers manufactured by J Sill Borosilicates, and filter paper by Whatman No. $2 \mathrm{~V}$ and of $18 \mathrm{~cm}$ diameter.

2.2. Instrumentation and Equipment. Automated sieve shaker by Matest-Treviolo (for sieving particles of coconut shells), Italy, UV mass spectrophotometer: 7310 visible Scanning Spectrophotometer fitted with $10 \times 10 \mathrm{~mm}$ cuvette holder, $320-1000 \mathrm{~nm}$ wavelength, resolution $=1 \mathrm{~nm}$ accuracy of $\pm 2 \mathrm{~nm}$, manufactured by Jenway (used to measure the transmittance and absorbance of filtrate/unabsorbed dye solution), muffle furnace with maximum temp. of $1300^{\circ} \mathrm{C}$ and 5-23 L chamber volume, made by Carbolite Gero (for heating the samples/carbonization), Oven Vs-1202d 3 made by Vision Scientific Co. Ltd. (for drying the samples), electronic weighing balance manufactured by Swastic Systems and Services, India (used to measure the weights of samples), $\mathrm{pH}$ meter (used to determine the $\mathrm{pH}$ of the activating agents and activated carbons), Orion ${ }^{\mathrm{TM}}$ Dual $\operatorname{Star}^{\mathrm{TM}} \mathrm{pH}$, ISE $\mathrm{Mv}$, ORP with temperature dual channel bench top meter manufactured by Thermo Fisher Scientific, and Joel Field Emission Electron Microscope JESM-7600F were used to obtain the elemental compositions of the activated carbons and visualize the surfaces of the samples.

\subsection{Mathematical Determination of Optimization Boundaries.} The Differential Response Technique was used to establish the experimental conditions and parameters of interest include carbonization temperature $X_{1}$ and concentration of reagent $X_{2}$ towards obtaining activated carbon of high adsorption capacity and economic viability. Central composite design was used to determine the minimum number of experiments required. We then calculated $N$ using

$$
N=2 n+2 n+n c=2(1)+2(1)+0=4,
$$

where $N$ is the total number of experiments required, $n c$ is center runs $(n c=0)$, and $n$ is the number of factors $(n=1)$. Hence, for minimum experimental runs, $N$ is given as 4 .

We modified the factorial design propounded by Karacan et al. [11]:

$$
\begin{aligned}
Y= & b_{0}+b_{1} X_{1}+b_{2} X_{2}+b_{3} X_{3}+b_{4} X_{1} X_{2}+b_{5} X_{1} X_{3} \\
& +b_{6} X_{2} X_{3}+b_{7} X_{1} X_{2} X_{3},
\end{aligned}
$$

where $Y$ is the yield, $b_{0}$ is the global mean, and $b_{i}$ represents the other regression coefficients, where $i=1,2,3, \ldots, j$.

The model formulation depends on carbon yield because it is common to all variables. The number of terms equals the number of experiments; hence

$$
Y=b_{0}+b_{1} X_{1} X_{2}+b_{2}\left(X_{1} X_{2}\right)^{2}
$$


For every difference in yield $(Y+\Delta Y)$, it is as a result of an increase in the input variables $\left(X_{1}+\Delta X_{1}\right)$ and $\left(X_{2}+\Delta X_{2}\right)$, therefore,

$$
\begin{aligned}
(Y+\Delta Y)= & b_{0}+b_{1}\left(X_{1}+\Delta X_{1}\right)\left(X_{2}+\Delta X_{2}\right) \\
& +b_{2}\left(\left(X_{1}+\Delta X_{1}\right)\left(X_{2}+\Delta X_{2}\right)\right)^{2}
\end{aligned}
$$

Subtract (3) from (4a)

$$
\begin{aligned}
\Delta Y= & b_{1} X_{2} \Delta X_{1}+b_{1} X_{1} \Delta X_{2}+b_{1} \Delta X_{1} \Delta X_{2} \\
& +2 b_{2} X_{1}^{2} X_{2} \Delta X_{2}+b_{2} X_{1}^{2} \Delta X_{2}^{2}+2 b_{2} X_{1} X_{2}^{2} \Delta X_{1} \\
& +4 b_{2} X_{1} X_{2} \Delta X_{1} \Delta X_{2}+2 b_{2} X_{1} \Delta X_{1} \Delta X_{2}^{2} \\
& +b_{2} X_{2}^{2} \Delta X_{1}^{2}+2 b_{2} X_{2} \Delta X_{1}^{2} \Delta X_{2} \\
& +b_{2} \Delta X_{1}{ }^{2} \Delta X_{2}^{2} .
\end{aligned}
$$

Divide through by $\Delta X_{1}$ and set $\Delta X_{1} \rightarrow 0$. The above equation then gives

$$
\begin{aligned}
\frac{d Y}{d X_{1}}= & b_{1}\left(X_{2}+\Delta X_{2}\right) \\
& +b_{2}\left(2 X_{1} X_{2}^{2}+4 X_{1} X_{2} \Delta X_{2}+2 X_{1} \Delta X_{2}^{2}\right), \\
\frac{d^{2} Y}{d X_{1}^{2}}= & b_{2}\left(2 X_{2}^{2}+4 X_{2} \Delta X_{2}+2 \Delta X_{2}^{2}\right) \\
= & 2 b_{2}\left(X_{2}+\Delta X_{2}\right)^{2} .
\end{aligned}
$$

We take the second differential equation by dividing (4a) through by $\Delta X_{2}$ and set $\Delta X_{2} \rightarrow 0$.

$$
\begin{aligned}
\frac{d Y}{d X_{2}}= & b_{1}\left(X_{1}+\Delta X_{1}\right) \\
& +b_{2}\left(2 X_{2} X_{1}^{2}+4 X_{1} X_{2} \Delta X_{1}+2 X_{2} \Delta X_{1}^{2}\right), \\
\frac{d^{2} Y}{d X_{2}^{2}}= & b_{2}\left(2 X_{1}^{2}+4 X_{1} \Delta X_{1}+2 \Delta X_{1}^{2}\right) \\
= & 2 b_{2}\left(X_{1}+\Delta X_{1}\right)^{2} .
\end{aligned}
$$

From (5),

$$
\frac{d^{2} Y}{d X_{1} X_{2}}=b_{1}+b_{2}\left(4 X_{1} X_{2}+4 X_{1}+2 X_{1} \Delta X_{2}\right) \text {. }
$$

From (6),

$$
\frac{d^{2} Y}{d X_{2} X_{1}}=b_{1}+b_{2}\left(4 X_{1} X_{2}+4 X_{2}+2 X_{2} \Delta X_{1}\right) \text {. }
$$

The coefficients in (5)-(9) above act as normalizing agents. The optimum condition for minimum experimental runs is very difficult to draw conclusions from; however, the DRT has the ability to monitor minute changes. The solution of (9) was chosen because of the role of concentration of chemical reagent for minimum experimental runs. However, we recommend the solutions of (5)-(8) for higher experimental runs. For economic reasons, few experimental runs were considered as they help to understudy the weaknesses and strengths of the approach adopted.

\section{Method}

3.1. Procedure. The procedure for preparing the activated carbon samples is discussed as follows.

3.1.1. Preparation of the Raw Material. Coconut shells of the West African tall tree variety, about $90 \mathrm{ft}$ tall, were collected from Okiewo in Edo state, Nigeria. To remove moisture, they were sun-dried for 3 days. The shells were pulverized and sieved using the $0.15 \mathrm{~mm}$ size sieve of the automated sieve shaker in order to obtain uniform fines with increased surface area.

3.1.2. Dye Solution for Adsorptive Performance Test. Methylene blue dye solution was used to test the performance of the activated carbons.

3.1.3. Calibration Curve for Methylene Blue. To test for the adsorptive performance of the activated carbon samples, a produced activated carbon sample was mixed with a $50 \mathrm{~mL}$ fixed concentration of methylene blue dye solution at $1 \mathrm{~g} / \mathrm{L}$ for 2 hours. The mixture was filtered and the filtrate was then analysed using a UV/Vis spectrophotometer to get the absorbance of dye solution. Different concentrations of dye solutions in the range of $1 \mathrm{mgL}^{-1}$ to $1000 \mathrm{mg} \mathrm{L}^{-1}$, as shown in Table 1, were prepared. They were each mixed with equal portions of the produced activated carbon. The mixtures were filtered and the filtrates were analysed using a UV/Vis spectrophotometer. A calibration graph (plot of absorbance against residual concentration of methylene blue solution, Beer Lambert's plot) was then obtained from which the absorbance of each activated carbon sample was determined. From (10), the adsorptive capacities of the activated carbon samples were calculated:

$$
\text { adsorptive capacity }(\%)=\frac{C_{o}-C}{C_{o}} \times 100,
$$

where $C_{o}$ is the initial concentration of dye; $C$ is the concentration of dye after adsorption.

\subsection{Experiments}

\subsubsection{Experiment 1}

Effect of Chemical Agent on Activated Carbon Performance and Yield. $100 \mathrm{~mL}$ solutions of $1 \mathrm{M} \mathrm{ZnCl}_{2}, \mathrm{KOH}$, and $\mathrm{H}_{3} \mathrm{PO}_{4}$ having $\mathrm{pH}$ of $5.26,11.18$, and 3.0 at $29^{\circ} \mathrm{C}$, respectively, were prepared. Three $7 \mathrm{~g}$ portions of the coconut shell samples prepared in Section 3.1.1 were weighed, mixed, and soaked for 24 hours in the $\mathrm{ZnCl}_{2}, \mathrm{KOH}$, and $\mathrm{H}_{3} \mathrm{PO}_{4}$ labelled $S_{1}, S_{2}$, and $S_{3}$, respectively. They were kept in an oven to dry at $105^{\circ} \mathrm{C}$. The samples were then heated in a muffle furnace at $575^{\circ} \mathrm{C}$. After one hour, the samples were washed with distilled water to remove the residual inorganic matter and excess chemical agent after which they were dried again in the oven at $105^{\circ} \mathrm{C}$ for 24 hours.

Another sample labelled $S_{4}$ (NAC), that is, coconut shell without any form of chemical impregnation, was prepared by the method described above. 
TABLE 1: Concentration variation with absorbance for the methylene blue solutions, methylene blue wavelength $(665 \mathrm{~nm})$.

\begin{tabular}{lc}
\hline Concentration $(\mathrm{mg} / \mathrm{L})$ & Absorbance \\
\hline 0 & 0 \\
1 & 0.263 \\
2 & 0.412 \\
10 & 1.424 \\
25 & 1.595 \\
50 & 1.653 \\
100 & 1.727 \\
125 & 1.754 \\
250 & 1.842 \\
375 & 1.909 \\
500 & 1.959 \\
625 & 1.992 \\
750 & 2.051 \\
1000 & 2.153 \\
\hline
\end{tabular}

The produced activated carbons from samples $S_{1}, S_{2}, S_{3}$, and $S_{4}$ were then weighed to evaluate their carbon yields. Thereafter, the procedure in Section 3.1.3 was used to determine the absorbance of the filtrates by adding $50 \mathrm{~mL}$ of the methylene blue dye prepared with the activated carbon for 2 hours and (10) was used to obtain their adsorption capacities.

\subsubsection{Experiment 2}

Effect of Concentration of Chemical Agent on Activated Carbon Performance and Yield. $\mathrm{H}_{3} \mathrm{PO}_{4}$ was chosen for this experiment because the sample activated with $\mathrm{H}_{3} \mathrm{PO}_{4}$ in Experiment 1 gave the best adsorptive performance; see Table 5. Five solutions of $0.3 \mathrm{M}, 0.5 \mathrm{M}, 0.67 \mathrm{M}, 1.00 \mathrm{M}$, and $1.33 \mathrm{M}$ of the acid were made. Five separate $7 \mathrm{~g}$ portions of the tall tree coconut shell samples were soaked separately in $100 \mathrm{~mL}$ of $0.3 \mathrm{M}, 0.5 \mathrm{M}, 0.67 \mathrm{M}, 1 \mathrm{M}$, and $1.33 \mathrm{M} \mathrm{H}_{3} \mathrm{PO}_{4}$ having $\mathrm{pH}$ of $2.2,2.17,2.07,1.98$, and 1.96 at $29^{\circ} \mathrm{C}$, respectively, for 24 hours. The samples were then labelled $A_{1}, A_{1.5}, A_{2}, A_{3}$, and $A_{4}$, respectively, before being heated in the oven at $105^{\circ} \mathrm{C}$.

In order to find out if the optimum concentration of $\mathrm{H}_{3} \mathrm{PO}_{4}$ for producing a very good activated carbon is general for all coconut varieties, shells from a Malayan Yellow Dwarf Variety sourced from Warri area of Delta State Nigeria were also collected, prepared, and processed to yield activated carbon using the procedure in Section 3.1.1 and the adsorptive performances of the carbon samples were determined using the method described in Section 3.2.1 but, here, four parts of the shells obtained from the dwarf variety each weighing $7 \mathrm{~g}$ were processed using $100 \mathrm{~mL} 0.3 \mathrm{M}, 0.67 \mathrm{M}, 1 \mathrm{M}$, and $1.33 \mathrm{M}$ $\mathrm{H}_{3} \mathrm{PO}_{4}$, respectively. The samples were labelled $A_{1 *}, A_{2 *}$, $A_{3 *}$, and $A_{4 *}$; see Tables 4 and 5 for the yields and adsorptive performance (as described in Section 3.2.1) of the activated carbon samples, respectively.

\subsubsection{Experiment 3}

Effect of Carbonization Temperature on Activated Carbon Performance and Yield. Four separate $100 \mathrm{~mL}$ solutions of
$0.67 \mathrm{M} \mathrm{H}_{3} \mathrm{PO}_{4}$ having a $\mathrm{pH}$ of 2.07 at $29^{\circ} \mathrm{C}$ were prepared; $0.67 \mathrm{M} \mathrm{H}_{3} \mathrm{PO}_{4}$ was selected for this experiment because, in Experiment 2, the activated carbon produced with $0.67 \mathrm{M}$ $\mathrm{H}_{3} \mathrm{PO}_{4}$ gave the best adsorptive performance.

Four parts of coconut shell samples were weighed and soaked in $100 \mathrm{~mL}$ of the four solutions for 24 hours. The first three samples labelled $B_{1}, B_{2}$, and $B_{3}$ weighed $7 \mathrm{~g}$ each while the last sample $\left(B_{4}\right)$ weighed $6.2 \mathrm{~g}$. The samples were dried in the oven at $105^{\circ} \mathrm{C}$. The samples were placed in the muffle furnace for carbonization at $450^{\circ} \mathrm{C}\left(B_{1}\right), 575^{\circ} \mathrm{C}\left(B_{2}\right), 700^{\circ} \mathrm{C}$ $\left(B_{3}\right)$, and $850^{\circ} \mathrm{C}\left(B_{4}\right)$ for 1 hour. The procedure in Section 3.2.1 was repeated so as to evaluate the yield of the activated carbon. In order to determine the adsorptive capacity of the carbon samples, the procedure in Section 3.1.3 was repeated using $50 \mathrm{~mL}$ dye solution at 2 hours of adsorption time.

\subsubsection{Experiment 4}

Effect of Chemical Agent on Physicochemical Properties of the Activated Carbon. In this experiment, the best tall tree variety activated carbon in Section 3.2.3 and commercial activated carbon (CAC) samples were tested for their moisture, ash, and volatile matter contents. Each sample was weighed and carbonized in the muffle furnace at $600^{\circ} \mathrm{C}$ for 1 hour; the properties were found as follows.

(i) Moisture Content. The mass of empty crucible with lid $\left(m_{1}\right)$ was first measured and recorded. The sample was then placed in the crucible and the total mass $m_{2}$ was measured. The crucible with sample in it but with its lid removed was heated in an oven at $150^{\circ} \mathrm{C}$. After 3 hours, the crucible was covered with its lid and the total mass $m_{3}$ was measured. Equation (11) was used to calculate the percent moisture removed from each sample:

$$
\text { moisture content }(\%)=100 \% \times \frac{\left(m_{1}-m_{2}\right)}{\left(m_{1}-m_{3}\right)} \text {, }
$$

where $m_{1}$ is the mass of empty crucible with lid (g); $m_{2}$ is the mass of crucible with lid and sample $(\mathrm{g}) ; m_{3}$ is the mass of crucible, lid, and dried sample (g).

(ii) Ash Content. Some of the sample that gave the best result in Section 3.2.3 was placed in an open crucible of mass $m_{4}$ and the total weight was recorded as $m_{5}$. The sample was placed in a muffle furnace whose temperature was adjusted to $650^{\circ} \mathrm{C}$. After 3 hours, the resultant weight $m_{5}$ of the crucible and contents was recorded. Using (12), the ash content of the activated carbon sample was obtained:

$$
\text { ash content }(\%)=100 \% \times \frac{\left(m_{6}-m_{4}\right)}{\left(m_{5}-m_{4}\right)} \text {, }
$$

where $m_{4}$ is the mass of empty crucible in $(\mathrm{g}) ; m_{5}$ is the mass of crucible plus original sample in $(\mathrm{g}) ; m_{6}$ is the mass of crucible plus ash in ( $\mathrm{g})$.

(iii) Volatile Matter Content. Some of the sample with best results in Section 3.2.3 was transferred into a crucible of mass 


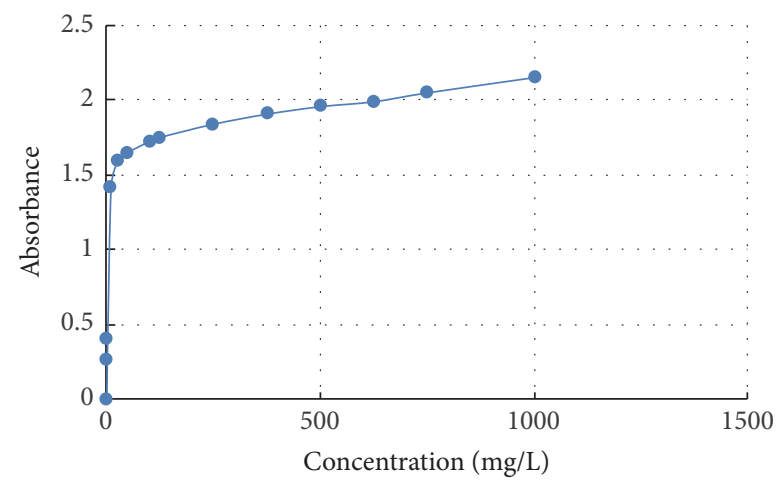

FIgURE 1: Absorbance versus concentration of the methylene blue dye.

$m_{4}$ and covered with lid; the total weight was recorded as $m_{7}$. The crucible with sample in it was then placed in the muffle furnace whose temperature was adjusted to $900^{\circ} \mathrm{C}$. After 7 minutes, the crucible was removed, allowed to cool, and reweighed; the mass was recorded as $m_{8}$. The volatile matter content of the activated carbon was obtained from

volatile matter content (\%)

$$
=100 \% \times \frac{\left[100\left(m_{7}-m_{3}\right)-m_{c}\left(m_{7}-m_{8}\right)\right]}{\left(m_{7}-m_{3}\right)\left(100-m_{c}\right)},
$$

where $m_{7}$ is the mass in $g$ of the crucible, lid, and sample before heating; $m_{8}$ is the mass in $\mathrm{g}$ of the crucible, lid, and content after heating; $m_{3}$ is the mass in $g$ of the empty crucible and lid; $m_{c}$ is the percentage by mass of moisture in the sample.

3.2.5. Surface Morphology and Elemental Compositions of Activated Carbons. The scanning electron microscope (JESM-7600F) was used to visualize the surfaces of the samples. The samples prepared were mounted on a doublesided carbon tape. The samples were exposed to an electron beam at an accelerating voltage of $15 \mathrm{keV}$ in order to obtain a signal for the SEM studies. The micromarker on the micrographs was used to estimate the pore size (diameter). The elemental composition, which is given in both atomic percent and weight percent that reflects the amount of a particular element in the analysed volume, was obtained with SEM.

\section{Results and Discussion}

4.1. The Calibration Curve. The calibration curve was drawn using the method discussed in Section 3.1.3 at a wavelength of $665 \mathrm{~nm}$. In Table 1, concentration of dye in the samples increased with absorbance and the highest absorbance was recorded for the $1000 \mathrm{mg} \mathrm{L}^{-1}$ solution. Figure 1 partly obeys Beer Lambert's law which states that a linear relationship exists between absorbance and concentration, although the law has conditions for nonlinearity especially for concentrations greater than $0.000001 \mathrm{M}$. The lowest concentration in

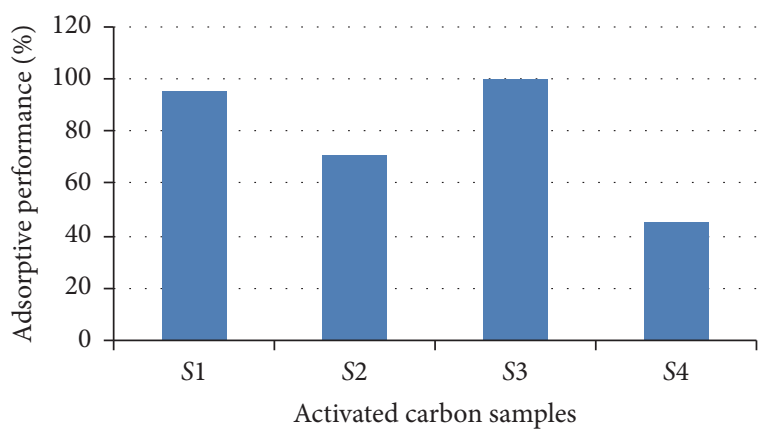

FIGURE 2: Adsorptive performance for activated carbon.

TABLE 2: Effect of activating agent on adsorptive performance.

\begin{tabular}{lccc}
\hline Sample & Activating agent & Absorbance & $\begin{array}{c}\text { Adsorptive } \\
\text { performance (\%) }\end{array}$ \\
\hline$S 1$ & $\mathrm{ZnCl}_{2}$ & 1.661 & 94.9 \\
$S 2$ & $\mathrm{KOH}$ & 1.87 & 70 \\
$S 3$ & $\mathrm{H}_{3} \mathrm{PO}_{4}$ & 0.166 & 99.9 \\
$S 4$ & $\mathrm{Nil}$ & 1.903 & 45 \\
\hline
\end{tabular}

the calibration curve of Figure 1 is $1 \mathrm{mgL}^{-1}$ which is equivalent to $0.0000031 \mathrm{M}$; hence, a nonlinear plot was obtained.

4.2. The Effect of Activating Agent on the Carbon. The effect of activating agent was determined in order to ascertain the following.

4.2.1. Adsorptive Performance. In Table 2 and Figure 2, the sample with the highest absorbance and adsorptive performance is $S_{4}$, that is, the NAC. Sample $S_{3}$ gave the least absorbance but the highest adsorptive performance of $99.9 \%$, hence, the most efficient adsorbent for methylene blue dye. Sample $S_{3}$ gave the best adsorptive performance followed by $S_{1}$ because the $\mathrm{H}_{3} \mathrm{PO}_{4}$ and $\mathrm{ZnCl}_{2}$ impregnated samples may have resulted in better developed pores compared to other samples at the stated conditions. $\mathrm{H}_{3} \mathrm{PO}_{4}$ in carbon precursors splits cellulose fibres and depolymerizes lignin and hemicellulose which results in mechanical resistance decline of the particle, inflammation of the material, and more cross-linked aromatic products. Additional cross-linking may be induced by the presence of phosphates [17]. $\mathrm{ZnCl}_{2}$ exhibits Bronstedacidity; hence, it donated protons to the particle which helped to break down the cellulose and lignin structures of the particle. Inflammation of the particles occurred as a result of the degradation; hence, there was reduction in mechanical resistance of the carbon particles. The presence of $\mathrm{ZnCl}_{2}$ and $\mathrm{H}_{3} \mathrm{PO}_{4}$ in the interior of the particles during carbonization gave rise to some degree of resistance to contraction of their pore volumes.

It was suspected that $\mathrm{KOH}$ did not react at the $575^{\circ} \mathrm{C}$; hence, it could not restrain the shrinking of the pore volume of the carbon particle. In addition, the porous structure of the sample was not well developed compared to those of 
TABLE 3: Effect of activating agent on activated carbon yield.

\begin{tabular}{lcc}
\hline Sample & Activating agent & Yield (\%) \\
\hline$S_{1}$ & $\mathrm{ZnCl}_{2}$ & 25 \\
$S_{2}$ & $\mathrm{KOH}$ & 18.3 \\
$S_{3}$ & $\mathrm{H}_{3} \mathrm{PO}_{4}$ & 23.3 \\
$S_{4}$ & $\mathrm{Nil}$ & 16.7 \\
\hline
\end{tabular}

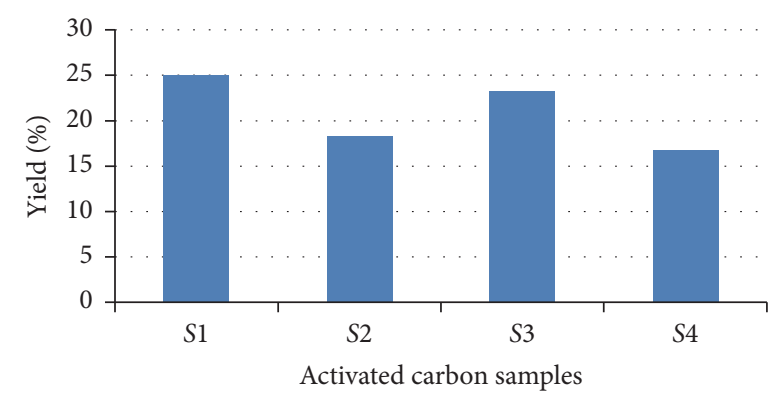

FIGURE 3: Chemical agent versus activated carbon yield.

samples $S_{1}$ and $S_{3}$. Also, the particles pore volume could have been blocked by products of decomposition which reduced its adsorptive capacity.

\subsubsection{Activated Carbon Yield}

(i) Effect of Type of Chemical Agent on Yield. In Table 3, sample $S_{1}$ gave the highest yield of $25 \%$ because it underwent the most efficient dehydration during carbonization. For carbonization to be highly effective, complete removal of oxygen and hydrogen is necessary. The degree of conversion of the precursor to carbon varies because of the loss of some amount of carbon with oxygen and hydrogen as $\mathrm{CO}_{2}, \mathrm{CO}$, or hydrocarbons. In $S_{1}$, the $\mathrm{ZnCl}_{2}$ fosters the removal of hydrogen and oxygen probably as water leaving behind the carbon atoms. According to [17], a typical lignocellulosic material comprises about $48 \%$ carbon. The highest yield of $25 \%$ was obtained probably because of several factors including the carbonization temperature and the $\mathrm{ZnCl}_{2}$ concentration used. Closest to the yield of $S_{1}$ is the yield from sample $S_{3}$ due to their similar dehydrating effect on the precursor; see Table 3 and Figure 3.

$18 \%$ yield was obtained for the $\mathrm{KOH}$ impregnated sample. The NAC sample gave the lowest yield because there was no dehydrating agent in the sample leading to loss of more carbon atoms along with hydrogen and oxygen; see Figure 3.

4.3. Effect of Activating Agent Concentration. The effect of activating agent concentration on activated carbon yield was obtained and the results are as seen in Table 4.

4.3.1. Effect of Activating Agent Concentration on Activated Carbon Yield. In Table 4, the sample impregnated with $1 \mathrm{M}$ $\mathrm{H}_{3} \mathrm{PO}_{4}$ gave the highest activated carbon yield while the sample impregnated with $0.3 \mathrm{M}$ of the acid gave the lowest yield for both samples, although that of the dwarf variety is higher; see Table 4. Figure 4(a) shows the variation of the activating agent concentration with activated carbon yield.

For the activated carbon samples $A_{1 *}, A_{2 *}, A_{3 *}$, and $A_{4 *}$, the yield of the activated carbon also increased with increased concentrations of $\mathrm{H}_{3} \mathrm{PO}_{4}$; see Table 4. The value recorded for $1.33 \mathrm{M}$ acid concentration $\left(A_{4 *}\right)$ is $40.1 \%$ which is $6 \%$ higher than the carbon yield obtained with $1 \mathrm{M}$ concentration of $\mathrm{H}_{3} \mathrm{PO}_{4}$. The trend observed can be likened to the dehydrating effect of $\mathrm{H}_{3} \mathrm{PO}_{4}$ on the precursors during carbonization. Also, samples with higher concentrations of $\mathrm{H}_{3} \mathrm{PO}_{4}$ up to $1.33 \mathrm{M}$ lost more atoms of oxygen and hydrogen extracted as water causing an increase in the activated carbon yield.

For sample $A_{4 *}$, the yield was less by $6 \%$ when compared to that of $A_{3 *}$; thus, the optimum $\mathrm{H}_{3} \mathrm{PO}_{4}$ concentration for preparing activated carbon of high yield, with little attention on performance for both species, is $1 \mathrm{M}$ based on the findings of this study; see Table 4 .

\subsubsection{Effect of Activating Agent Concentration on Adsorptive} Performance of Activated Carbon. Based on the DRT, (9) was used to simulate the optimum conditions discussed in Figures 4(b) and 4(c). Figure 4(b) shows an optimization process when temperature controls the chemical reaction. The variation between $0.3 \mathrm{M}$ and $0.97 \mathrm{M}$ shows that processing activated carbon within this concentration range may positively increase the expected carbon yield; this agrees with the experimental results. The results in Figure 4(c) show that concentration may not have positive influence on the yield if further increased. Again, this agrees well with our experiment since, for the tall tree variety, the sample with the best adsorptive performance is the sample impregnated with $0.67 \mathrm{M} \mathrm{H}_{3} \mathrm{PO}_{4}$ as described in Section 3.2.2; hence this is the reason it was chosen for the analysis. The carbonization temperature for all samples was $575^{\circ} \mathrm{C}$ and the activation time was 1 hour. $A_{1}, A_{1.5}, A_{2}$, and $A_{3}$ were the activated carbon samples produced using $\mathrm{H}_{3} \mathrm{PO}_{4}$ impregnation at $0.3 \mathrm{M}, 0.5 \mathrm{M}, 0.67 \mathrm{M}$, and $1 \mathrm{M}$ concentrations, respectively. However, in Table 5, samples $A_{2}$ and $A_{1.5}$ gave the best adsorptive performance of $100 \%$ with corresponding absorbance of 0.04 and 0.07 , respectively, whereas, for samples $A_{1 *}-A_{4 *}$ of the dwarf variety, the sample with the best adsorptive performance was sample $A_{3 *}$ with adsorptive performance of $99.9 \%$ and absorbance of 0.76 . While the operating conditions remain unaltered, in order that the adsorptive capacity of the activated carbon is maximized, the acid concentration must be kept between 0.3 and $0.67 \mathrm{M}$ for the tall tree sample but between 0.3 and $1 \mathrm{M}$ for the dwarf variety because the activated carbon pore structure tends to be destroyed or expanded above the stated concentrations of $\mathrm{H}_{3} \mathrm{PO}_{4}$ which in turn reduces their adsorptive capacities; see Figure 5. Again, for the tall tree variety, sample $A_{3}$ shows the highest absorbance but least performance. Absorbance is higher for sample $A_{1}$ than $A_{2}$. Therefore, the adsorptive performance increased with acid concentration from 0.3 to $0.67 \mathrm{M}$. The lower performance of sample $A_{3}$ may be due to excessive breakdown of the cellulose structure which may cause very little or no modification in the micropores at $575^{\circ} \mathrm{C}$. Figures $7(\mathrm{a})$ and $7(\mathrm{~b})$ give an overview of $\mathrm{B} 1$ and its pore size distribution as obtained from SEM analyses. 


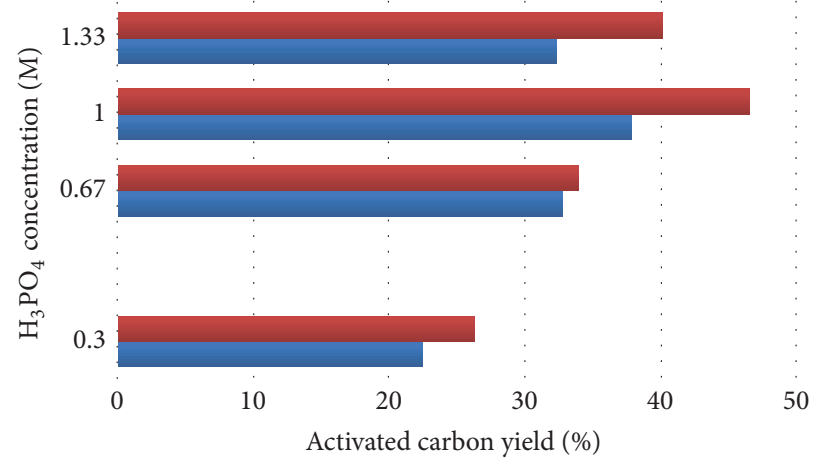

- Dwarf tree variety

- Tall tree variety

(a) Activating agent concentration variation with activated carbon yield.
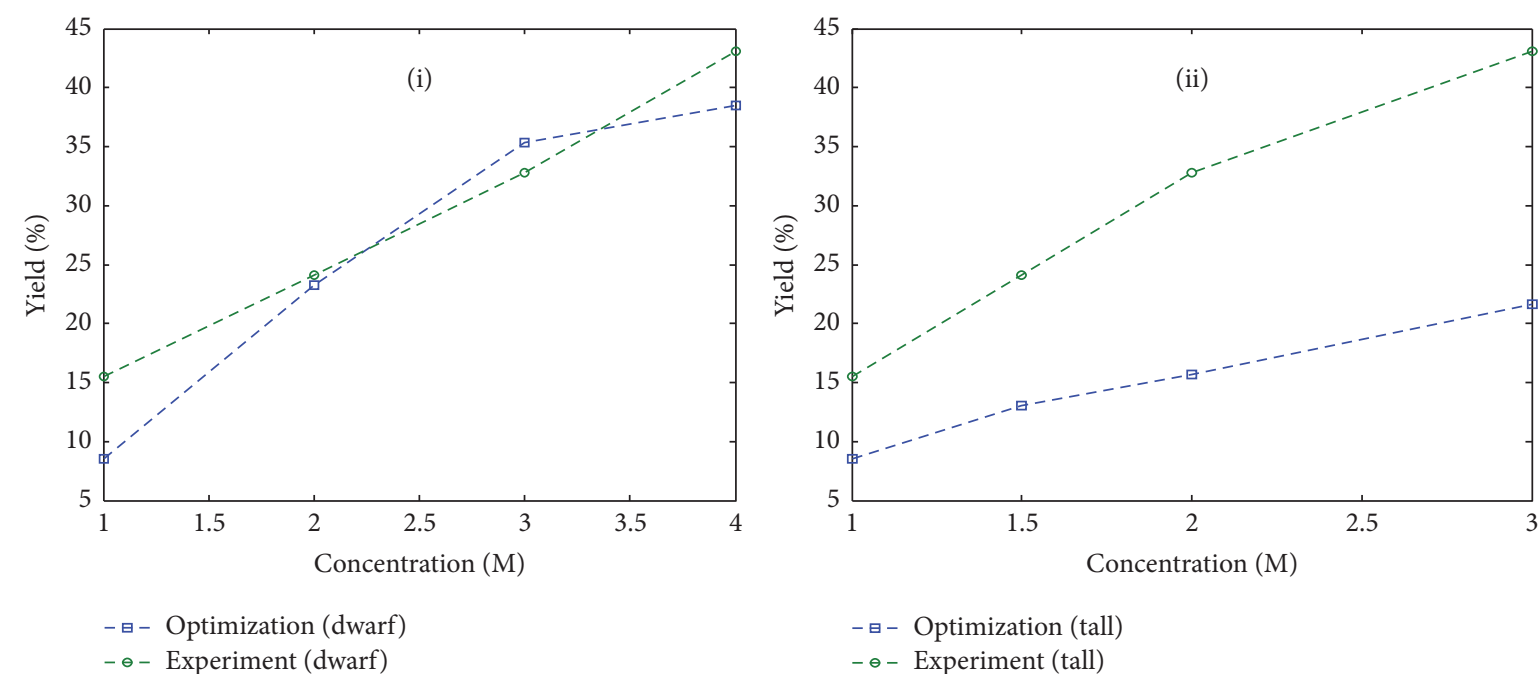

- - Optimization (dwarf)

$-\ominus-$ Experiment (dwarf)

$-\theta-$ Experiment (tall)

(b) Activating agent concentration variation with activated carbon yield for (i) dwarf variety and (ii) tall tree variety (when $b_{1}=0.0000118$ and $b_{2}=0.0000149$ ).
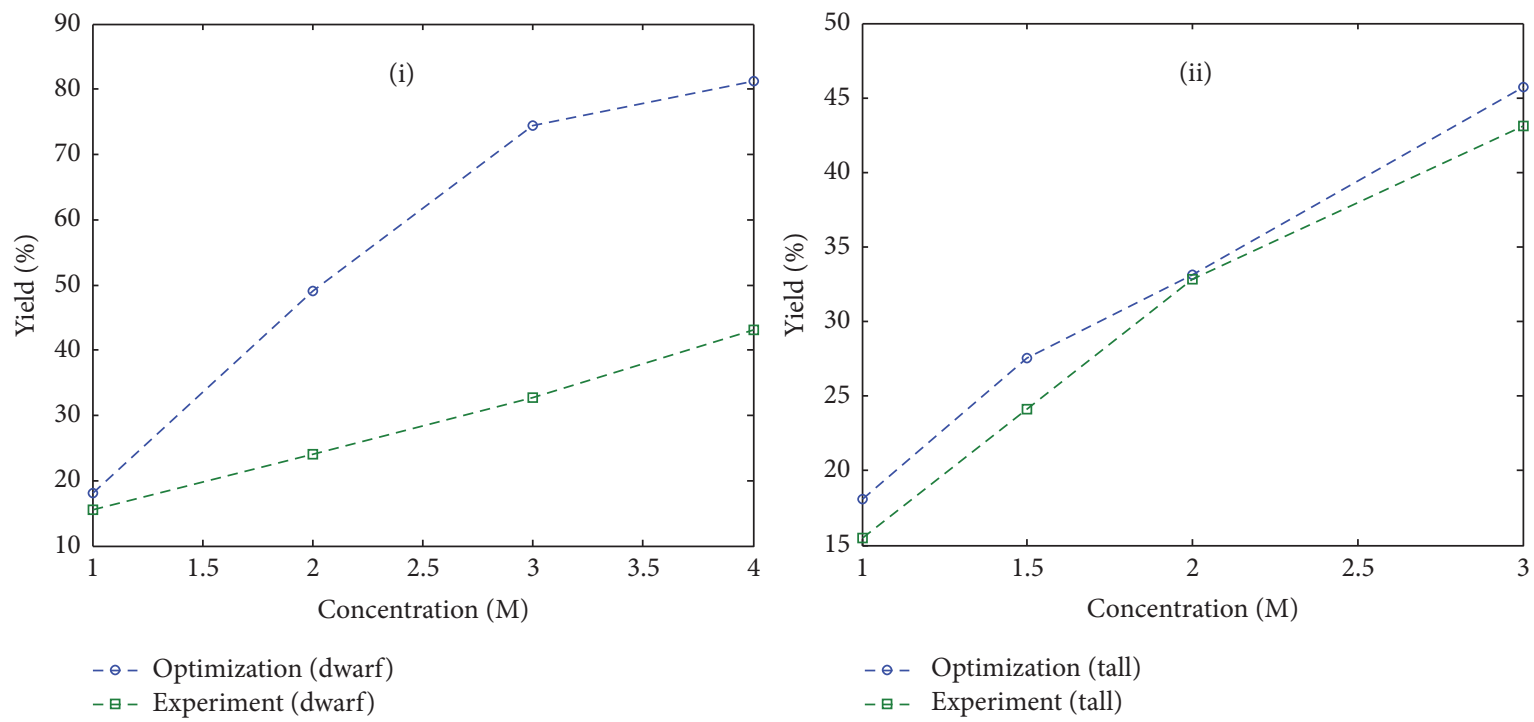

$-\ominus-$ Optimization (dwarf)

$-\bullet-$ Experiment (tall)

(c) Activating agent concentration variation with activated carbon yield for (i) dwarf variety and (ii) tall tree variety (when $b_{1}=0.000000149$ and $b_{2}=0.0000249$ at higher concentrations).

FIGURE 4 
TABLE 4: Effect of activating agent concentration on activated carbon yield.

\begin{tabular}{lccc}
\hline Samples & $\mathrm{H}_{3} \mathrm{PO}_{4}$ concentration $(\mathrm{M})$ & $\begin{array}{c}\text { Tall tree variety yield } \\
(\%)(A 1-A 4) \text { at } 575^{\circ} \mathrm{C}\end{array}$ & $\begin{array}{c}\text { Dwarf tree variety } \\
\text { yield }(\%)(A 1 *-A 4 *) \\
\text { at } 575^{\circ} \mathrm{C}\end{array}$ \\
\hline$A_{1}, A_{1 *}$ & 0.30 & 22.4 & 26.3 \\
$A_{1.5},-$ & 0.50 & 24.1 & - \\
$A_{2}, A_{2 *}$ & 0.67 & 32.8 & 34.0 \\
$A_{3}, A_{3 *}$ & 1.00 & 37.9 & 46.6 \\
$A_{4}, A_{4 *}$ & 1.33 & 32.3 & 40.1 \\
\hline
\end{tabular}

TABLE 5: Effect of activating agent concentration on absorbance and adsorptive performance.

\begin{tabular}{lccc}
\hline Sample & $\begin{array}{c}\mathrm{H}_{3} \mathrm{PO}_{4} \\
\text { concentration }(\mathrm{M})\end{array}$ & Absorbance & $\begin{array}{c}\text { Adsorptive } \\
\text { performance (\%) }\end{array}$ \\
\hline$A_{1}, A_{1 *}$ & 0.30 & $0.116,2.29$ & $99.9,97$ \\
$A_{1.5},-$ & 0.50 & 0.066 & $100,-$ \\
$A_{2}, A_{2 *}$ & 0.67 & $0.04,1.76$ & $100,99.7$ \\
$A_{3}, A_{3 *}$ & 1.00 & $1.707,0.77$ & $91.5,99.9$ \\
$A_{4}, A_{4 *}$ & 1.33 & $2.36,3.187$ & $80.2,71.4$ \\
\hline
\end{tabular}

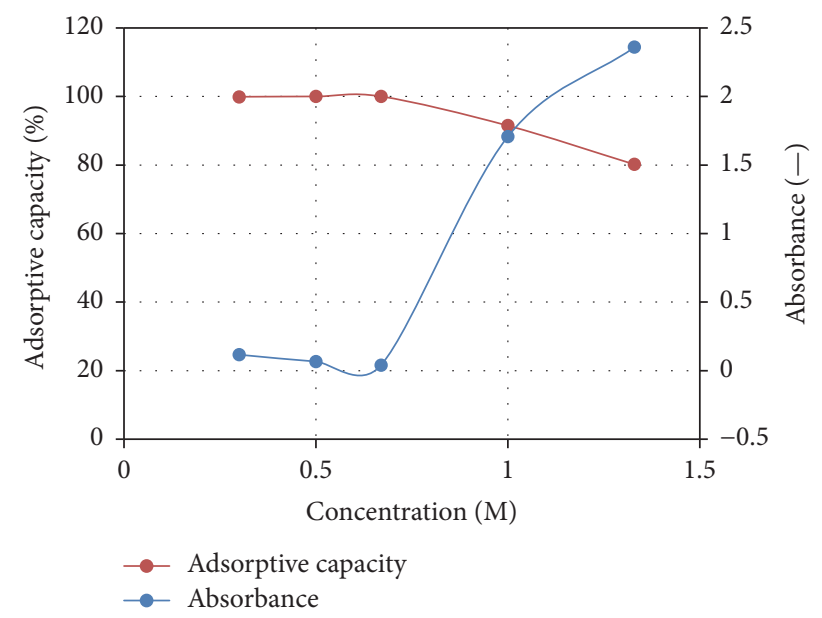

Figure 5: Profile of concentration of $\mathrm{H}_{3} \mathrm{PO}_{4}$ with absorbance and adsorptive performance samples.

\subsection{The Effect of Carbonization Temperature on Activated Carbon Yield}

4.4.1. Effect of Carbonization Temperature on Adsorptive Performance of Carbon. In Experiment 3, all samples were impregnated with $0.67 \mathrm{M}$ concentration of $\mathrm{H}_{3} \mathrm{PO}_{4}$. Table 6 shows the results obtained for the different samples. There was a slight increase in the adsorptive performance from $99.8 \%$ to $100 \%$ due to an increase in the carbonization temperature from $450^{\circ} \mathrm{C}$ to $575^{\circ} \mathrm{C}$. At $575^{\circ} \mathrm{C}$, it could be seen that the results from the scanning electron microscope (SEM) analysis show that more defined/finer pores were
TABLE 6: Variation of temperature with activated carbon yield for tall tree variety.

\begin{tabular}{lccc}
\hline Sample & $\begin{array}{c}\text { Carbonization } \\
\text { temperature }\left({ }^{\circ} \mathrm{C}\right)\end{array}$ & Performance (\%) & Yield (\%) \\
\hline$B_{1}$ & 450 & 99.8 & 43.1 \\
$B_{2}$ & 575 & 100.0 & 32.8 \\
$B_{3}$ & 700 & 94.8 & 24.1 \\
$B_{4}$ & 850 & 94.8 & 15.5 \\
\hline
\end{tabular}

formed leading to a higher internal surface area and improved adsorptive properties of $B_{2}$; see Figures $8(a)$ and $8(\mathrm{~b})$ for the structural morphology and pore size distribution of $B_{2}$ (i.e., in the range of $0.62 \mu \mathrm{m}-1.76 \mu \mathrm{m}$ ) as compared to the morphology and pore size distribution (i.e., in the range of $0.73-2.57$ ) for $B_{1}$. Also, a decrease in the adsorptive performance of the activated carbon from $100 \%$ to $94.8 \%$ was observed for samples $B_{3}$ and $B_{4}$, with pore sizes in the range of $0.68-1.50 \mu \mathrm{m}$ and $0.77-3.77 \mu \mathrm{m}$, respectively, for an increase in the carbonization temperature from $575^{\circ} \mathrm{C}$ to $850^{\circ} \mathrm{C}$; see Figures 9(a) and 9(b) and Figures 10(a) and 10(b) for the structural morphologies and pore size distributions of the activated carbons formed at both temperatures, respectively. This may be due to excessive carbonization causing distortion or further expansion of other pore walls between successive neighbouring pores. Furthermore, the phosphate and polyphosphate links formed during the condensation reaction become volatile above $650^{\circ} \mathrm{C}$ which makes it difficult for these compounds to be able to inhibit contraction of the pore volume thus, giving a decrease in porosity and adsorptive characteristic of the particle.

For the dwarf variety, sample $A_{3 *}$ gave even pore size distribution, that is, $1.80 \mu \mathrm{m}$, while for sample $A_{4}$ the pore size distribution is in the range of $0.53-0.68 \mu \mathrm{m}$; see Figures 11(a) and 11(b) and 12(a) and 12(b) respectively, for their morphologies and pore size distributions.

4.4.2. Effect of Carbonization Temperature on Activated Carbon Yield. In Table 6 and Figure 6(a), the activated carbon yield reduced at temperatures above $450^{\circ} \mathrm{C}$; the same can be seen in Figure 6(b). The decrease in yield was as a result of the expulsion of phosphate compounds and volatile matter from the samples and this is in agreement with the results 


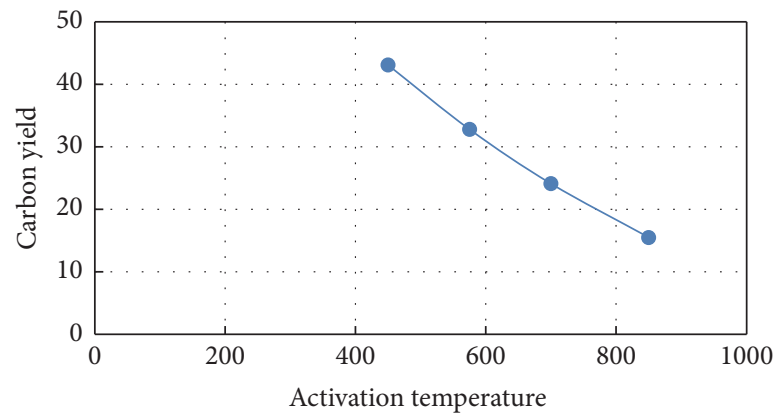

(a) Carbonization temperature variation with carbon yield for the tall tree variety.
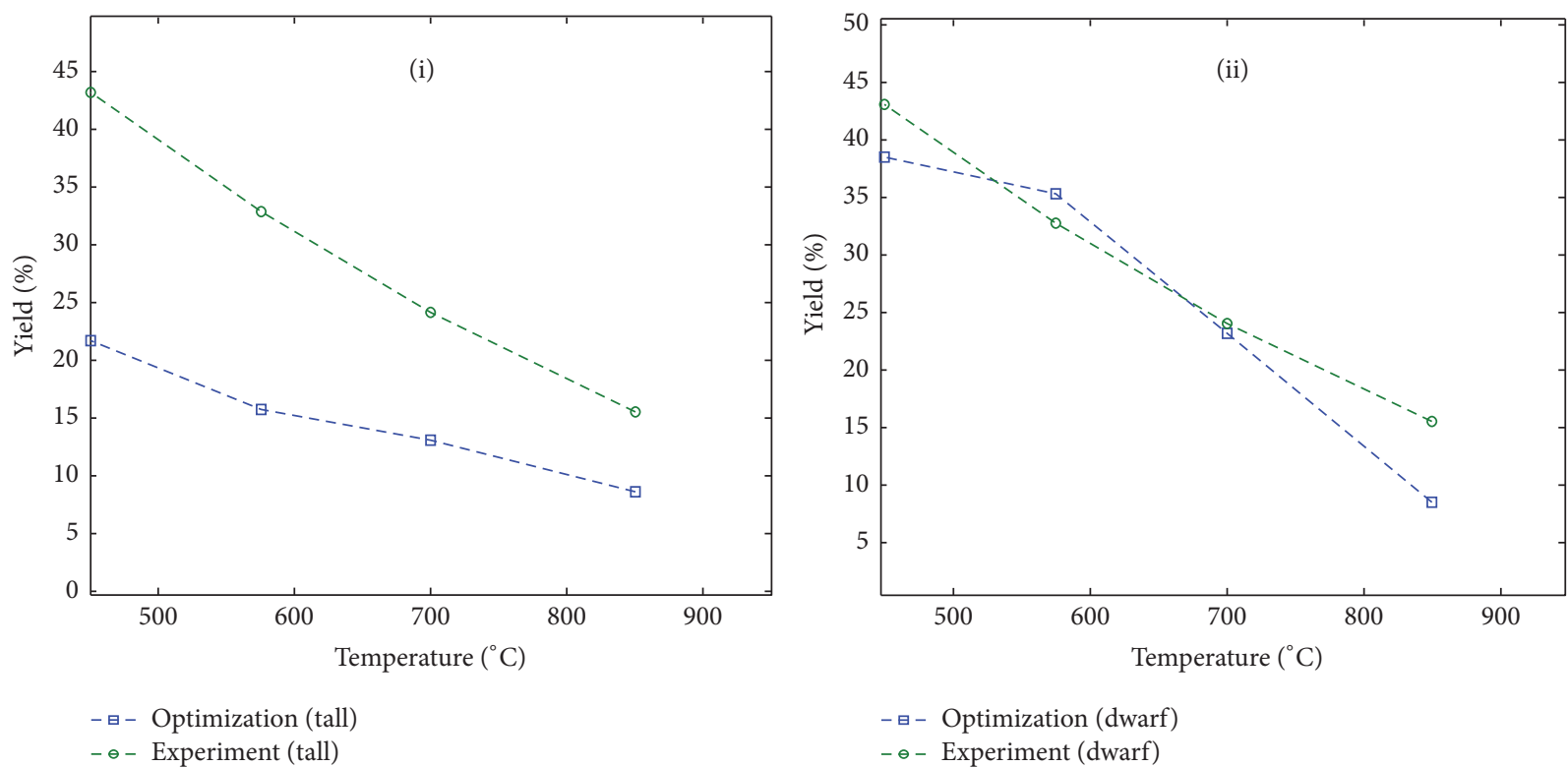

(b) Carbonization temperature variation with carbon yield for (i) tall tree variety and (ii) dwarf variety (when $b_{1}=0.0000118$ and $b_{2}=0.0000149$ ).
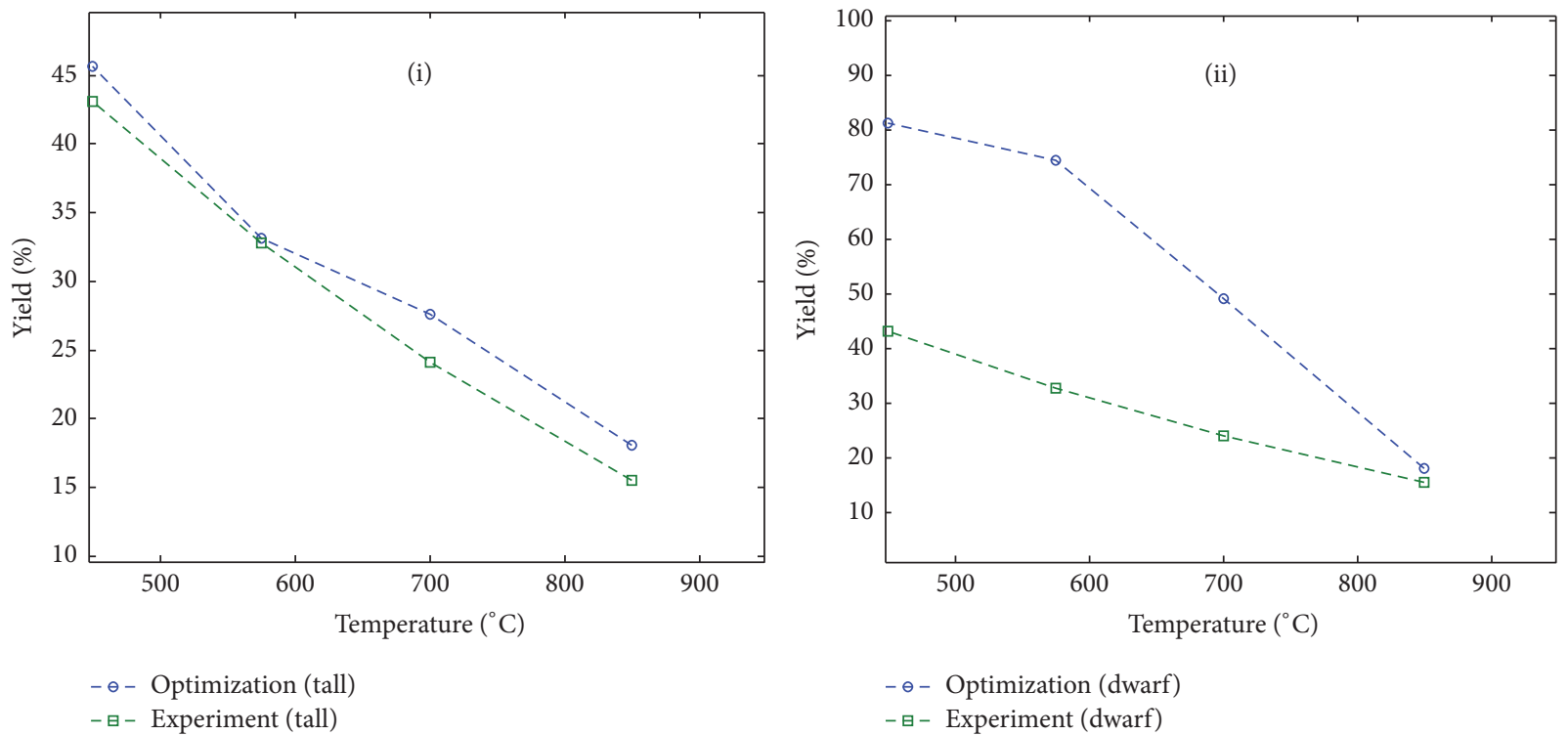

(c) Carbonization temperature variation with carbon yield for (i) tall tree variety and (ii) dwarf variety (when $b_{1}=0.000000149$ and $b_{2}=0.0000249$ ). 


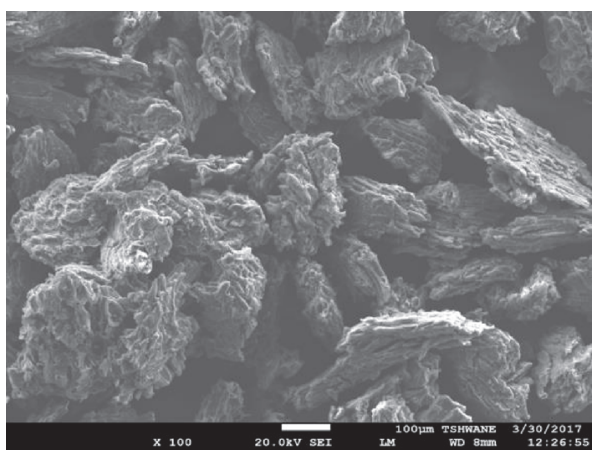

(a)

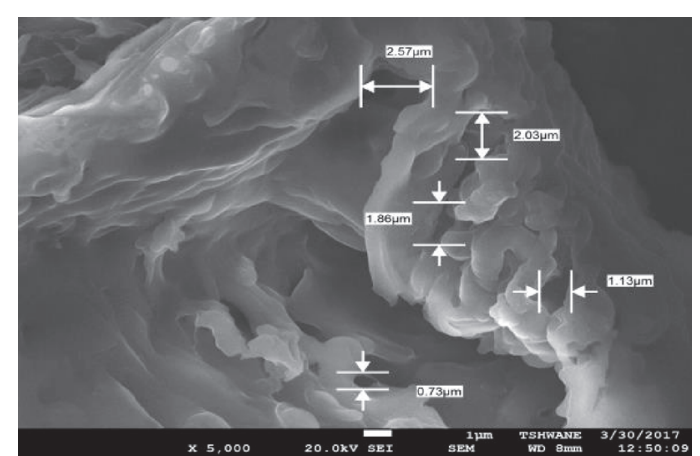

(b)

FIGURE 7: (a) Overview of $B_{1}$ from SEM analysis; (b) pore size distribution of $B_{1}$ at $\times 5000$ magnification.

TABLE 7: Adsorptive performance and absorbance of the synthesized and commercial activated carbons.

\begin{tabular}{lcc}
\hline Material & Absorbance & Adsorptive performance (\%) \\
\hline Sample $B_{2}$ & 0.04 & 100 \\
Commercial AC & 0.023 & 100 \\
\hline
\end{tabular}

of Ip et al. [9]. Higher temperatures of 575 to $850^{\circ} \mathrm{C}$ alter the mesoporous and macroporous structures of the particles and under these conditions, the yield dropped to 15.5\%; the highest yield was obtained at $450^{\circ} \mathrm{C}$; hence, in order to maximize the yield, the carbonization temperature should be kept at $450^{\circ} \mathrm{C}$ which corresponds to an activated carbon yield of $43.1 \%$.

In Figure 6(b), based on the model, the variation between $450^{\circ} \mathrm{C}$ and $850^{\circ} \mathrm{C}$ shows that processing activated carbon at higher temperatures will decrease the expected yield. We also considered a condition when concentration controls the chemical reaction; see Figures 4(b) and 4(c). This shows that concentration of the acid has influence on the yield if further increased which agrees well with the experimental data despite the slight deviations.

\subsection{Comparing the Sample Activated Carbon with Commercial} Activated Carbon. In Table 7, comparing $B_{2}$ and the CAC, a similar adsorptive performance of $100 \%$ is indicative of good product efficiency and quality, although the absorbance of the CAC is slightly lower which may be due to the type of activating agent, nature of precursor, carbonization temperature, and concentration of the active agent used to produce the CAC.

4.6. Physicochemical Properties of the Sample Activated Carbon. In Table 8 , the physicochemical properties of the activated carbon $B_{2}$ obtained in Section 3.2.4 are shown with those of the NAC sample.

(i) Moisture Content. According to Indo German Carbons Limited, the moisture content of activated carbon should be $\leq 6 \%$. Under standard conditions, moisture has no effect on the performance of activated carbon. The moisture content
TABLE 8: Physicochemical properties of the synthesized and commercial activated carbons.

\begin{tabular}{lccc}
\hline Carbon sample & $\begin{array}{c}\text { Moisture } \\
\text { content, \% }\end{array}$ & Ash content, \% & $\begin{array}{c}\text { Volatile } \\
\text { matter, \% }\end{array}$ \\
\hline CAC & 5 & 5.28 & 68.4 \\
$B_{2}$ & 7 & 7.2 & 57 \\
\hline
\end{tabular}

of the NAC sample was $5 \%$ while that of $B_{2}$ was $7 \%$ because the $\mathrm{H}_{3} \mathrm{PO}_{4}$ used to impregnate the activated carbon sample was in its aqueous state which added more water to sample $B_{2}$.

(ii) Ash Content. $B_{2}$ gave ash of about $7.2 \%$ while the NAC gave $5.28 \%$ ash. This is because the phosphate compounds formed by the acid in $B_{2}$ increased the volume of the inorganic matter in the activated carbon thus increasing the amount of nonignitable residue left in the furnace. The smaller \% ash in the NAC sample is likened to the lack of chemical agent within the precursor. Based on literature, the ash content of CAC is between 2 and $10 \%$; hence that of $B_{2}$ is acceptable since high percent ash reduces the efficiency of reactivation/regeneration of activated carbons.

(iii) Volatile Matter. From the experiment, sample $B_{2}$ was seen to contain less volatile matter relative to the NAC whose values are $57 \%$ and $68.4 \%$, respectively. Sample $B_{2}$ had lower volatile contents because $\mathrm{H}_{3} \mathrm{PO}_{4}$ forms phosphates and polyphosphate esters with hydrogen and oxygen atoms which would have been given off as gases during the carbonization process. Also, the dehydrating effect of the acid caused the water in the material to vaporize; hence, the covalent bond in the carbon matrix was therefore strengthened leaving no room for carbon loss. For the NAC sample, it lacked any chemical agent that could bring about those reactions. Also, the carbon matrix is weaker than that of sample $B_{2}$ which makes for possible loss of carbon atoms in gaseous forms.

The elemental composition of sample $B_{2}$ can be found in Table 9 which shows the percentage composition of the atoms in the activated carbon. The percentage atom of carbon in the sample is $88.46 \%$ and that of oxygen is $11.04 \%$ while 


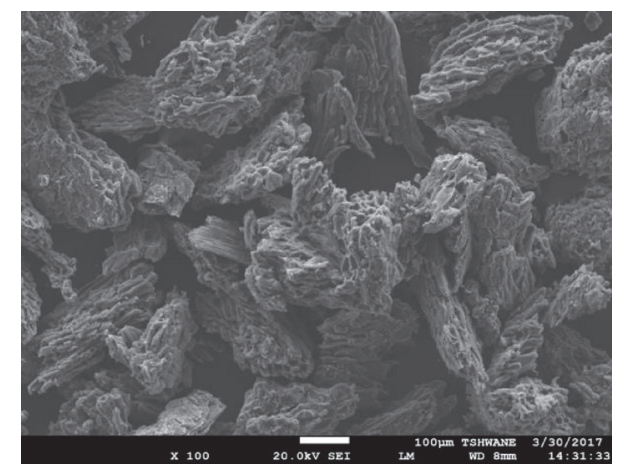

(a)

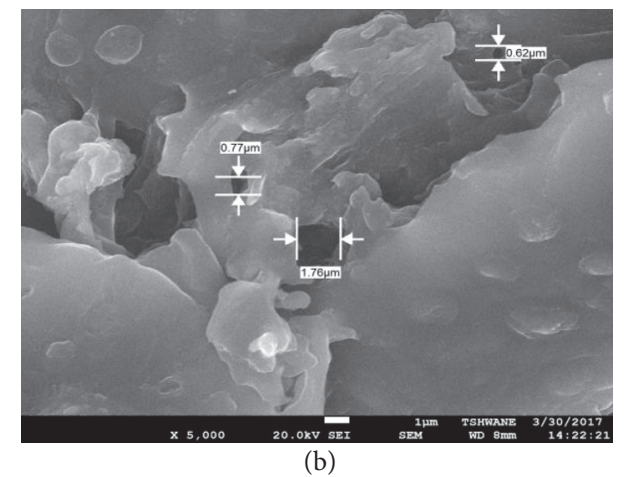

(a) Overview of $B_{2}$ from SEM analysis.

(b) Pore size distribution of $B_{2}$ at $\times 5000$ magnification.

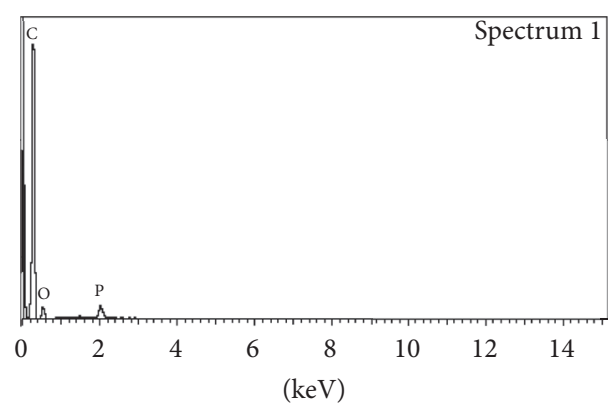

Full scale 6877 cts cursor: 0.000

(c)

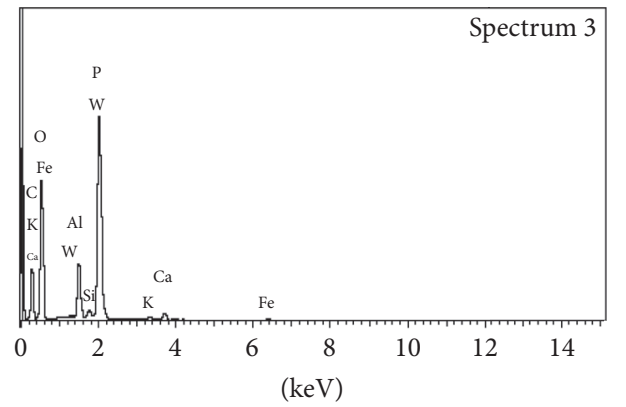

Full scale 6877 cts cursor: 0.000

(d)

(c) Atomic spectrum of $B_{2}$ at $600 \mu \mathrm{m}$ wavelength.

(d) Atomic spectrum of $A_{3 *}$ at $10 \mu \mathrm{m}$ wavelength.

Figure 8 


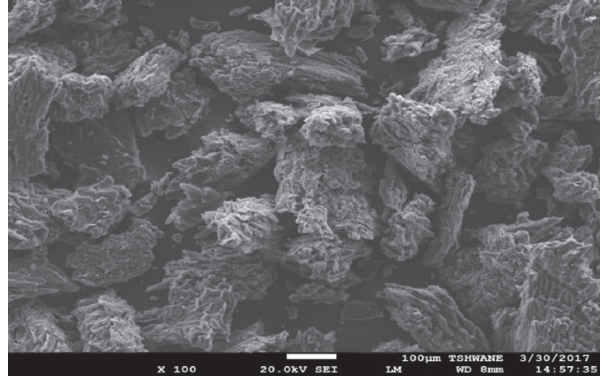

(a)

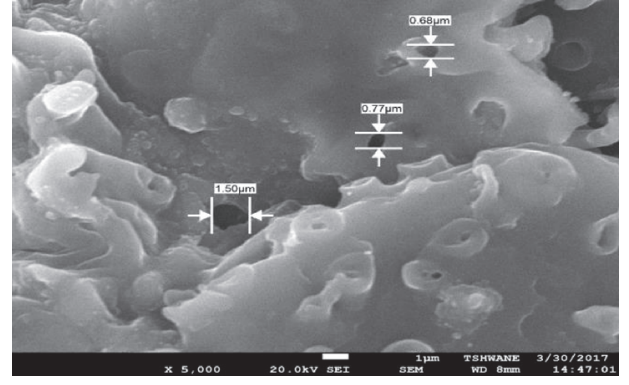

(b)

Figure 9: (a) Overview of $B_{3}$ from SEM analysis; (b) pore size distribution of $B_{3}$ at $\times 5000$ magnification.

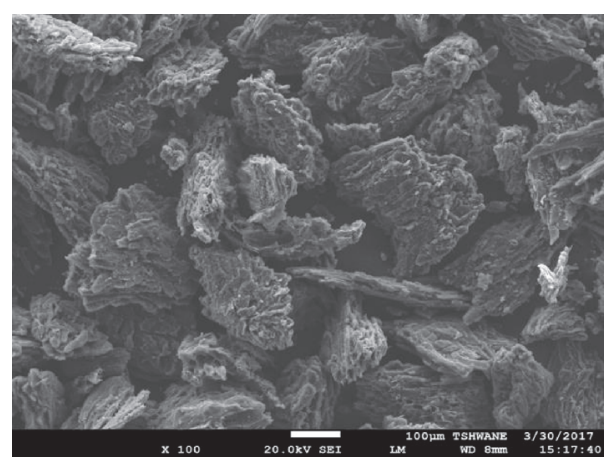

(a)

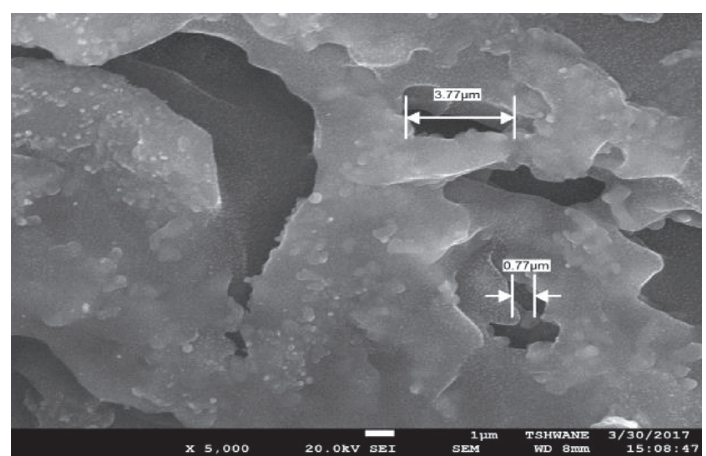

(b)

FIGURE 10: (a) Overview of $B_{4}$ from SEM analysis; (b) pore size distribution of $B_{4}$ at $\times 5000$ magnification.

TABLE 9: Elemental composition of $B_{2}$.

\begin{tabular}{lcc}
\hline Element & Weight\% & Atomic\% \\
\hline C K & 84.69 & 88.46 \\
O K & 14.07 & 11.04 \\
P K & 1.24 & 0.50 \\
\hline Total & 100.00 & 100.00 \\
\hline
\end{tabular}

for phosphorus trace amount, that is, $0.5 \%$, was found; see also Figure $8(\mathrm{c})$ for the atomic spectrum of $B_{2}$ at $600 \mu \mathrm{m}$ wavelength. Figure $8(\mathrm{~d})$ shows the atomic spectrum of $A_{3 *}$ with percent weight of carbon, oxygen, aluminium, silicon, phosphorus, potassium, calcium, and iron of $36.85 \%, 45.53 \%$, $2.82 \%, 0.27 \%, 12.72 \%, 0.2 \%, 0.57 \%, 0.56 \%, 0.36 \%$, and $0.7 \%$; that is, the amount of oxygen present is higher than the amount of carbon. Also, the sample can be seen to have high amount of impurities.

4.7. Solutions $p H$ and $p H$ of Activated Carbon. The $p H$ values of the reagents used are as documented in Table 10. The degrees of acidities of the acid solutions are seen to increase with decreased $\mathrm{pH}$. The optimum $\mathrm{pH}$ for $0.67 \mathrm{M}$ concentration of the $\mathrm{H}_{3} \mathrm{PO}_{4}$ required for making activated carbon of excellent performance from the tall tree variety coconut shell is 2.07 while that for the dwarf variety is 1.98 . The $\mathrm{pH}$ of $B_{2}$ is 2.20 while that of $A_{3 *}$ is 2.08 ; these values are indicative of the medium/media for activation.

4.8. Statistical Analyses of Model. Statistical analyses of the performance of the model was carried out considering the model predictions shown in Figures 4(b)(i) and (ii), 4(c)(i) and (ii), 6(b)(i) and (ii), and 6(c)(i) and (ii). Table 11 shows that the confidence interval of the model predictions lies between 95 and $99 \%$ with the correlation coefficients of the model for concentration effect on yield in Figures 4(b) and $4(c)(i)$ in the range of $96-99 \%$, while the correlation coefficients for effect of temperature variation on the yield for both varieties as shown in Figures 6(b) and 6(c)(i) and (ii), for both varieties as predicted by the model, are in the range of 96\%-99\%, which shows that the model predictions agree well with experimental data; see Tables 11 and 12.

\section{Conclusion}

Coconut shell activated carbon with excellent adsorptive properties can be produced using $\mathrm{H}_{3} \mathrm{PO}_{4}$ concentrations between 0.3 and $1 \mathrm{M}$. $0.67 \mathrm{M}$ phosphoric acid gave the best adsorptive performance and absorbance for the activated carbon synthesized from the tall tree variety. Increase in carbonization temperature caused a decrease in the activated 


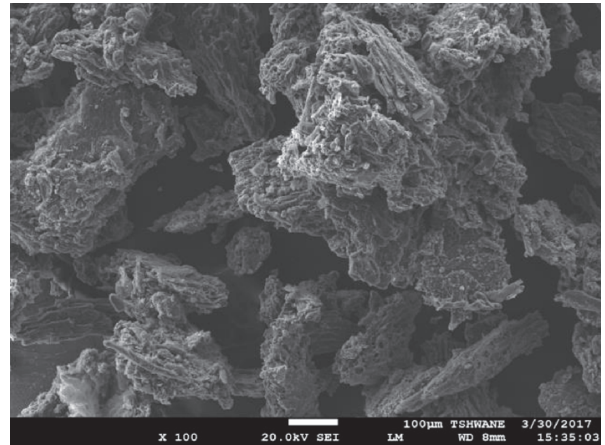

(a)

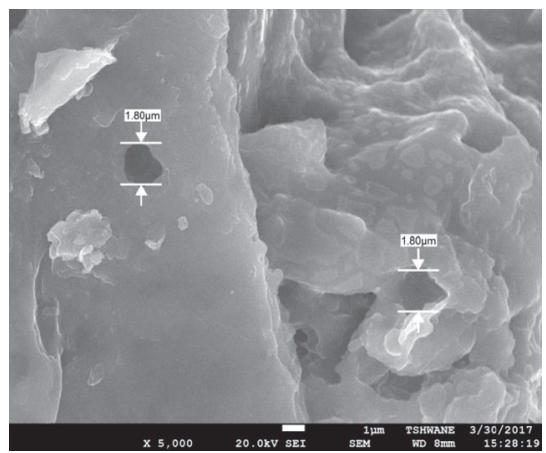

(b)

Figure 11: (a) Overview of $A_{3 *}$ from SEM analysis; (b) pore size distribution of $A_{3 *}$ at $\times 5000$ magnification.

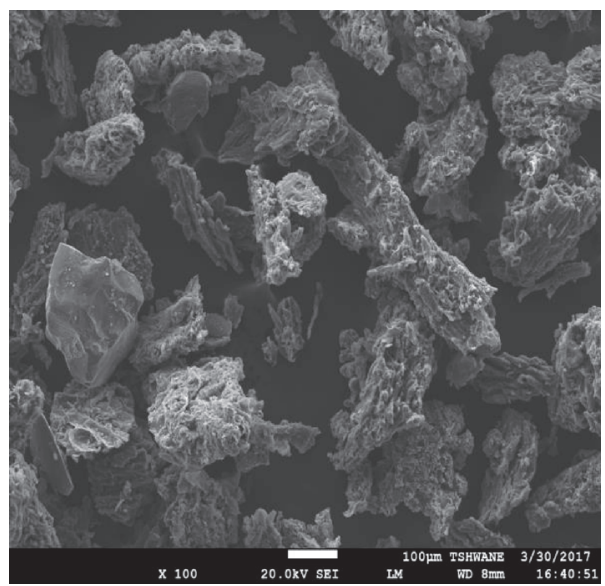

(a)

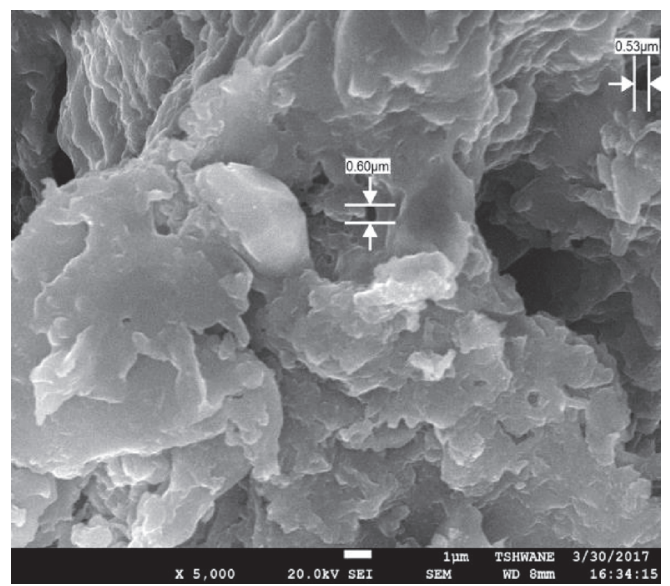

(b)

FIgure 12: (a) Overview of $A_{4 *}$ from SEM analysis; (b) pore size distribution of $A_{4 *}$ at $\times 5000$ magnification.

carbon yield. Activated carbon produced at $575^{\circ} \mathrm{C}$ gave the highest adsorptive performance of $100 \%$. However, because of the relative difference (10\%) in activated carbon yield of $B_{1}$ relative to $B_{2}$ and the slight variation of $0.2 \%$ in their adsorptive performances, the optimum temperature for producing activated carbon of the tall tree variety therefore lies between 450 and $575^{\circ} \mathrm{C}$. The activating agents increased the ash and moisture contents of the carbon particles and decreased their volatile constituents. Based on the findings of this research, the optimum $\mathrm{H}_{3} \mathrm{PO}_{4}$ concentration and $\mathrm{pH}$ for preparing activated carbon of high yield from the tall and the dwarf variety coconut shells are $0.67 \mathrm{M}$ and 2.07, respectively; higher concentrations above the optimum value gave lower yields for both varieties. The optimum temperatures were found to be in the range of $450-575^{\circ} \mathrm{C}$ for the tall tree variety coconut shell activated carbon, while, for the dwarf variety activated carbon, the optimum temperature was found to be $575^{\circ} \mathrm{C}$. Also, based on the results in Table 10, the optimum $\mathrm{pH}$ for producing activated carbon with the best adsorptive performance using phosphoric acid from the tall tree variety is 2.07 while that of the dwarf variety was found to be 1.98 of the acid solution. Based on the statistical analyses, the model's confidence interval between 95 and 99\% gives correlation coefficient values with levels of accuracy in the range of 96-99\%; hence, the model results agree well with data generated experimentally.

\section{Nomenclature}

\section{Letters}

$C$ : Dye concentration after adsorption, $\left[\mathrm{gL}^{-1}\right]$

$N$ : Number of experiments, (-)

$n$ : Number of factors, $(-)$

$Y$ : Yield, [\%]

\section{Greek Symbols}

$\Delta X_{1}$ : Change in concentration, $\left[\mathrm{gL}^{-1}\right]$

$\Delta X_{2}$ : Change in temperature, $\left[{ }^{\circ} \mathrm{C}\right]$

$\Delta Y:$ Change in yield, [\%]. 
TABLE 10: $\mathrm{pH}$ of the solutions (activating agents).

\begin{tabular}{|c|c|c|c|c|c|c|}
\hline $\begin{array}{l}\mathrm{ZnCl}_{2} \\
1 \mathrm{M} \\
29^{\circ} \mathrm{C}\end{array}$ & $\begin{array}{c}\mathrm{KOH}, \\
1 \mathrm{M} \\
29^{\circ} \mathrm{C}\end{array}$ & $\begin{array}{c}\left(0.3 \mathrm{M} \mathrm{H}_{3} \mathrm{PO}_{4}\right) \\
29^{\circ} \mathrm{C}\end{array}$ & $\begin{array}{c}\left(0.5 \mathrm{M} \mathrm{H}_{3} \mathrm{PO}_{4}\right) \\
29^{\circ} \mathrm{C}\end{array}$ & $\begin{array}{c}\left(0.67 \mathrm{M} \mathrm{H}_{3} \mathrm{PO}_{4}\right) \\
29^{\circ} \mathrm{C}\end{array}$ & $\begin{array}{c}\left(1.00 \mathrm{M} \mathrm{H}_{3} \mathrm{PO}_{4}\right) \\
29^{\circ} \mathrm{C}\end{array}$ & $\begin{array}{c}1.33 \mathrm{M}\left(\mathrm{H}_{3} \mathrm{PO}_{4}\right) \\
29^{\circ} \mathrm{C}\end{array}$ \\
\hline 5.26 & 11.18 & 2.20 & 2.17 & 2.07 & 1.98 & 1.96 \\
\hline
\end{tabular}

TABLE 11: Statistical analysis of model.

\begin{tabular}{lcccc}
\hline Item measured & $\begin{array}{c}\text { Optimization (dwarf) } \\
\text { Figure 4(b)(i) }\end{array}$ & $\begin{array}{c}\text { Optimization (tall) } \\
\text { Figure 4(b)(ii) }\end{array}$ & $\begin{array}{c}\text { Optimization (dwarf) } \\
\text { Figure 4(c)(i) }\end{array}$ & $\begin{array}{c}\text { Optimization (tall) } \\
\text { Figure 4(c)(ii) }\end{array}$ \\
\hline Standard error & 2.735 & 6.796 & 14.334 & 5.7687 \\
$95 \%$ confidence interval & 8.704 & 21.625 & 45.611 & 18.356 \\
99\% confidence interval & 15.98 & 39.696 & 83.725 & 33.695 \\
Standard deviation & 5.471 & 13.592 & 28.668 & 11.537 \\
Coefficient of variation & 0.371 & 0.5146 & 0.5148 & 0.371 \\
Correlation with experiment & 0.994 & 0.9559 & 0.9559 & 0.9936 \\
\hline
\end{tabular}

TABLE 12: Statistical analysis of model.

\begin{tabular}{lcccc}
\hline Item measured & $\begin{array}{c}\text { Optimization (tall) } \\
\text { Figure 6(b)(i) }\end{array}$ & $\begin{array}{c}\text { Optimization (dwarf) } \\
\text { Figure 6(b)(ii) }\end{array}$ & $\begin{array}{c}\text { Optimization (tall) } \\
\text { Figure 6(c)(i) }\end{array}$ & $\begin{array}{c}\text { Optimization (dwarf) } \\
\text { Figure 6(c)(ii) }\end{array}$ \\
\hline Standard error & 6.796 & 2.7353 & 5.769 & 14.334 \\
95\% confidence interval & 21.625 & 8.7037 & 18.36 & 45.611 \\
99\% confidence interval & 39.696 & 15.977 & 33.69 & 83.725 \\
Standard deviation & 13.592 & 5.4706 & 11.54 & 28.668 \\
Coefficient of variation & 0.5146 & 0.3708 & 0.371 & 0.5148 \\
Correlation with experiment & 0.9559 & 0.9936 & 0.994 & 0.9559 \\
\hline
\end{tabular}

\section{Sub-and Superscripts}

$A_{1}$ : Tall tree variety sample with $0.3 \mathrm{M}$ phosphoric acid concentration

$A_{1.5}$ : Tall tree variety sample with $0.5 \mathrm{M}$ phosphoric acid concentration

$A_{2}$ : Tall tree variety sample with $0.67 \mathrm{M}$ phosphoric acid concentration

$A_{3}$ : Tall tree variety sample with $1 \mathrm{M}$ phosphoric acid concentration

$A_{4}$ : Tall tree variety sample with $1.33 \mathrm{M}$ phosphoric acid concentration

$A_{1 *}$ : Dwarf tree variety sample with $0.3 \mathrm{M}$ phosphoric acid concentration

$A_{2 *}$ : Dwarf tree variety sample with $0.67 \mathrm{M}$ phosphoric acid concentration

$A_{3 *}$ : Dwarf tree variety sample with $1 \mathrm{M}$ phosphoric acid concentration

$A_{4 *}$ : Dwarf tree variety sample with $1.33 \mathrm{M}$ phosphoric acid concentration

$B_{1}$ : Tall tree sample with $0.67 \mathrm{M}$ phosphoric acid carbonized at $450^{\circ} \mathrm{C}$

$B_{2}$ : Tall tree sample with $0.67 \mathrm{M}$ phosphoric acid carbonized at $575^{\circ} \mathrm{C}$

$B_{3}$ : Tall tree sample with $0.67 \mathrm{M}$ phosphoric acid carbonized at $700^{\circ} \mathrm{C}$
$B_{4}$ : Tall tree sample with $0.67 \mathrm{M}$ phosphoric acid carbonized at $850^{\circ} \mathrm{C}$

$b_{0}$ : Constant (global mean), $(-)$

$b_{1}$ : Coefficient, $(-)$

$b_{2}$ : Coefficient, $(-)$

$b_{3}$ : Coefficient, $(-)$

$b_{4}$ : Coefficient, (-)

$b_{5}$ : Coefficient, $(-)$

$b_{6}$ : Coefficient, $(-)$

$b_{7}$ : Coefficient, $(-)$

$C_{0}$ : Initial dye concentration, $\left[\mathrm{gL}^{-1}\right]$

$m_{1}$ : Mass of container with lid plus original sample, [g]

$m_{2}$ : Mass of container with lid plus dried sample, $[\mathrm{g}]$

$m_{3}$ : Mass of container with lid, $[\mathrm{g}]$

$m_{4}$ : Mass of empty crucible, [g]

$m_{5}$ : Mass of crucible plus original sample, [g]

$m_{6}$ : Mass of crucible plus ash, [g]

$m_{7}$ : Mass in $g$ of the crucible, lid, and sample before heating, $[\mathrm{g}]$

$m_{8}$ : Mass in $g$ of the crucible, lid, and content after heating, [g]

$m_{c}$ : Percentage by mass of moisture in the sample, [\%] 


\author{
$n_{c}: \quad$ Number of center runs, $(-)$ \\ $S_{1}: \quad$ Sample activated with $\mathrm{ZnCl}_{2},(-)$ \\ $S_{2}$ : $\quad$ Sample activated with $\mathrm{H}_{3} \mathrm{PO}_{4},(-)$ \\ $S_{3}: \quad$ Sample activated with $\mathrm{KOH},(-)$ \\ $S_{4}$ : $\quad$ Tall tree variety sample without any activat- \\ ing agent \\ $X_{1}: \quad$ Concentration term, $\left[\mathrm{gL}^{-1}\right]$ \\ $X_{2}: \quad$ Temperature term, $\left[{ }^{\circ} \mathrm{C}\right]$ \\ $d Y / d X_{1}$ : Change in yield with concentration, $\left[\mathrm{Lg}^{-1}\right]$ \\ $d Y / d X_{2}$ : Change in yield with temperature, $\left[{ }^{\circ} \mathrm{C}^{-1}\right]$.
}

\section{Abbreviations}

NAC: Nonactivated carbon

CAC: Commercial activated carbon.

\section{Conflicts of Interest}

The authors declare that they have no conflicts of interest.

\section{Acknowledgments}

The authors wish to thank Covenant University for its support in providing the facilities for this research and part sponsorship. Also, our appreciation goes to Samuel Sanni for planning the project execution and preparing the manuscript; Joseph Odigure for conceptualizing the research and initiating the experimental design and editing the manuscript; Moses Emetere for modelling the process; Vincent Efeovbokhan for his contribution, editing, and useful suggestions at different stages of the work; Oluranti Agboola and Emmanuel Sadiku for the SEM analyses and revision of manuscript.

\section{References}

[1] A. A. Awoyale, A. C. Eloka-Eboka, and O. A. Odubiyi, "Production and experimental efficiency of activated carbon from local waste bamboo for waste water treatment," International Journal of Engineering and Applied Sciences, vol. 3, no. 2, pp. 1-10, 2013.

[2] M. A. Baghapour, B. Djahed, and M. Ranjbar, "Removal of methylene blue from aqueous solutions by waste paper derived activated carbon," Journal of Health Science Surveillance Systems, vol. 1, no. 1, pp. 48-56, 2013.

[3] R. C. Basal, Activated Carbon Adsorption, Dekker/CRC Press, Boca Raton, FL, USA, 1937.

[4] C. Gimba, [Ph.D. thesis], Ahmadu Bello University, Zaria, Nigeria, 2001.

[5] M. K. B. Gratuito, T. Panyathanmaporn, R. A. Chumnanklang, and A. Dutta, "Production of activated carbon from coconut shell: optimization using response surface methodology," Bioresource Technology, vol. 99, no. 11, pp. 4887-4895, 2008.

[6] R. H. Gumus and I. Okpeku, "Production of activated carbon and characterization from snail shell waste (helix pomatia)," Advances in Chemical Engineering and Science, vol. 5, pp. 51-61, 2015.

[7] R. H. Hesas, A. Arami-Niya, W. M. A. Daud, and J. N. Sahu, "Preparation and characterization of activated carbon from apple waste by micro-assisted phosphoric acid activation: application in methylene blue adsorption," Bioresources.com, pp. 1-17, 2013.

[8] J. J. Hung, [B.Eng. thesis], Department of Chemical Engineering, University of Arizona, USA, 2012.

[9] A. W. M. Ip, J. P. Barford, and G. Mckay, "Production and comparison of high surface area bamboo derived active carbons," Bioresource Technology, vol. 6, pp. 6809-6816, 2008.

[10] H. Jankowska, A. Swiatkowski, and J. E. H. Choma, Active Carbon, West Sussex, England and Prentice-Hall, Englewood Cliffs, New Jersey, NJ, USA, 1991.

[11] F. Karacan, U. Ozden, and S. Karacan, "Optimization of manufacturing conditions for activated carbon from Turkish lignite by chemical activation using response surface methodology," Applied Thermal Engineering, vol. 27, no. 7, pp. 1212-1218, 2007.

[12] J. M. Ketcha, D. J. M. Dina, H. M. Ngomo, and N. J. Ndi, "Preparation and characterization of activated carbons obtained from maize cobs by zinc chloride activation," American Chemical Science Journal, vol. 4, pp. 136-160, 2012.

[13] X. Long, H. Chang, and W. Yuan, "Reduction of hexamine cobalt (III) catalyzed by coconut activated carbon," Environment Bryer and Sustainable Energy, vol. 29, no. 1, pp. 85-92, 2010.

[14] P. A. M. Mourão, C. Laginhas, F. Custódio, J. M. V. Nabais, P. J. M. Carrott, and M. M. L. R. Carrott, "Influence of oxidation process on the adsorption capacity of activated carbons from lignocellulosic precursors," Fuel Processing Technology, vol. 92, no. 2, pp. 241-246, 2011.

[15] O. E. Odebunmi and O. F. Okeola, "Preparation and characterization of activated carbon from waste material," Journal of Chemical Society of Nigeria, vol. 26, no. 2, pp. 1-7, 2001.

[16] N. H. Phan, S. Rio, C. Faur, L. Le Coq, P. Le Cloirec, and T. H. Nguyen, "Production of fibrous activated carbons from natural cellulose (jute, coconut) fibers for water treatment applications," Carbon, vol. 44, no. 12, pp. 2569-2577, 2006.

[17] F. Rodriguez-Reinoso, M. Molina-Sabio, and M. Gonzalez, "The use of steam and $\mathrm{CO}$ as activating agents in the preparation of activated carbons," Carbon, vol. 33, no. 1, pp. 15-23, 1995.

[18] J. Romanos, M. Beckner, T. Rash et al., "Nanospace engineering of $\mathrm{KOH}$ activated carbon," Nanotechnology, vol. 23, no. 1, pp. 15401-15407, 2012.

[19] U. Sains and N. Sembilan, "Preparation and characterization of activated carbon from desiccated coconut residue by potassium hydroxide," Asian Journal of Chemistry, vol. 27, no. 6, pp. 23312336, 2015.

[20] T. Shalna and A. Yogamoorthi, "Preparation and characterization of activated carbon from used tea dust in comparison with commercial activated carbon," International Journal of Recent Scientific Research, vol. 6, no. 2, pp. 2750-2755.

[21] O. A. Sodeinde, "Preparation of a locally produced activated carbon from coconut shells and its use in reducing hexamine cobalt III," International Journal of Chemical Engineering and Applications, vol. 3, no. 1, pp. 1-5.

[22] M. Soleimani and T. Kagazchi, "Low-Cost adsorbents from agricultural by-products impregnated with phosphoric acid," Advanced Chemical Engineering Research, vol. 3, pp. 1-8, 2014.

[23] P. Susheela and R. Radha, "Production of activated carbon from dry coconut shell and its efficacy in treating waste water," International Journal of Chemical and Biological Sciences, vol. 1, no. 10, pp. 1-9.

[24] C. Srinivasakannan and M. Abu Bakar, "Production of activated carbon from rubber wood sawdust," Biomass and Bioenergy, vol. 27, no. 1, pp. 89-96, 2004. 
[25] N. A. Taha, S. E. Abdelhafez, and A. El-Maghraby, "Chemical and physical preparation of activated carbon using raw bagasse pith for cationic dye adsorption," Global Nest Journal, vol. 18, no. 2, pp. 1-14, 2016

[26] I. A. W. Tan, A. L. Ahmad, and B. H. Hameed, "Preparation of activated carbon from coconut husk: optimization study on removal of 2,4,6-trichlorophenol using response surface methodology," Journal of Hazardous Materials, vol. 153, no. 1-2, pp. 709-717, 2008. 


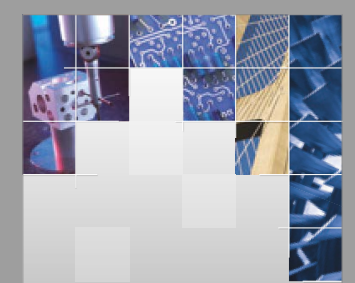

\section{Enfincering}
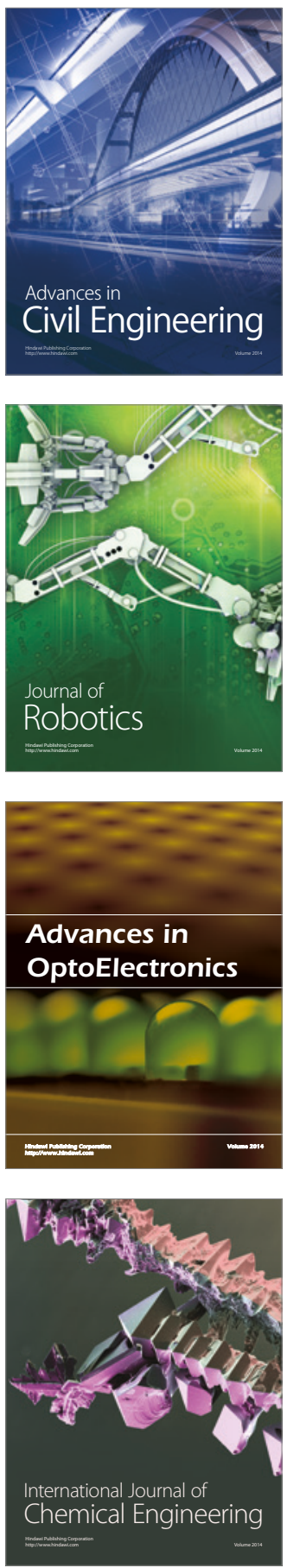

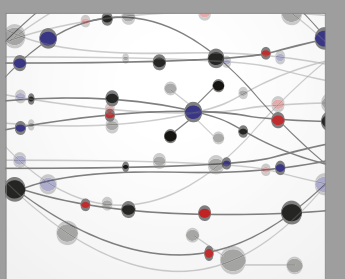

The Scientific World Journal

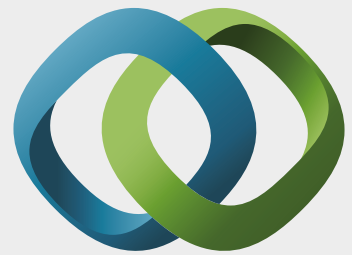

\section{Hindawi}

Submit your manuscripts at

https://www.hindawi.com
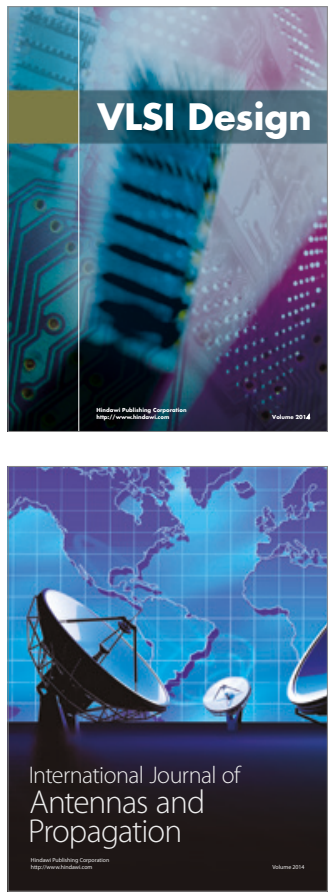

\section{Rotating}

Machinery
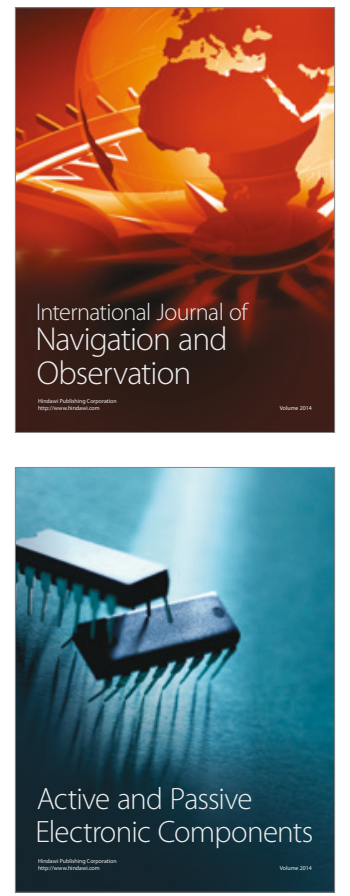
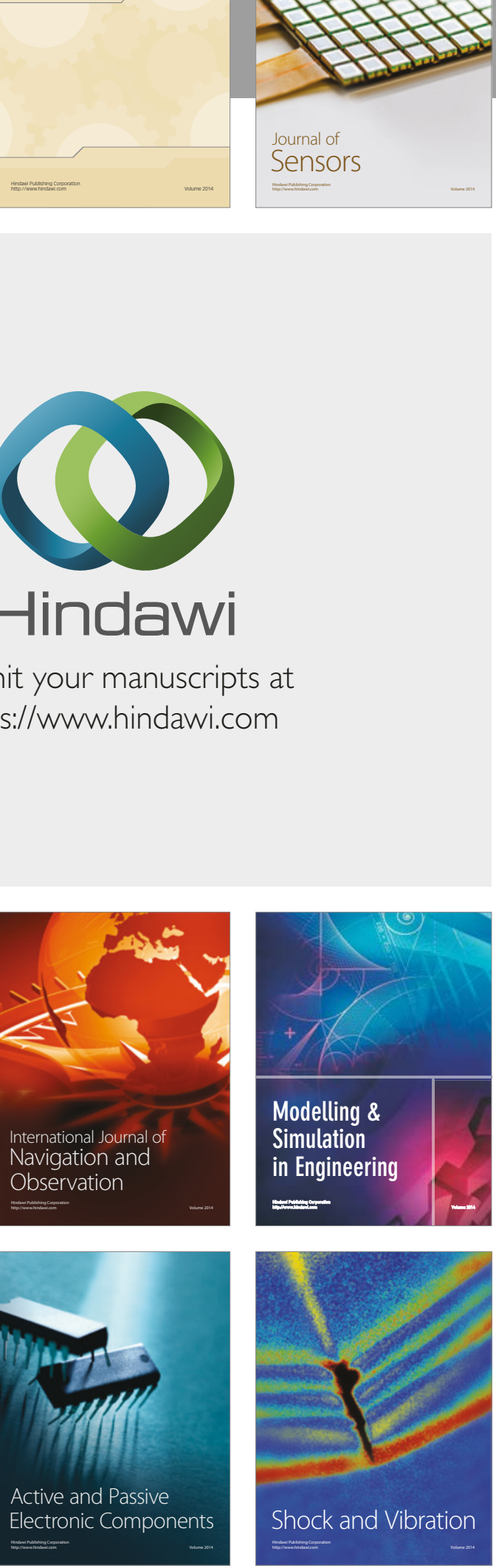
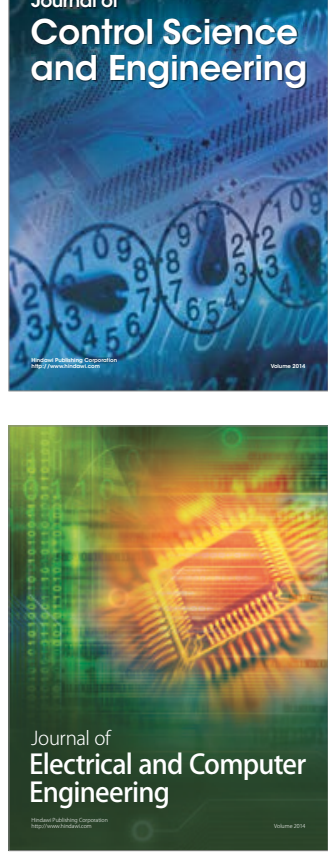

Distributed

Journal of

Control Science

and Engineering
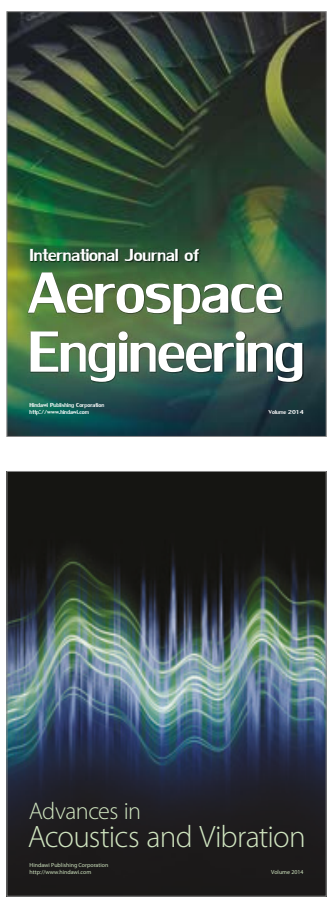

Sensor Networks 